\title{
Engineered nanomaterials: exposures, hazards, and risk prevention
}

\author{
Robert A Yokel ${ }^{*}$, Robert C MacPhail ${ }^{2}$
}

\begin{abstract}
Nanotechnology presents the possibility of revolutionizing many aspects of our lives. People in many settings (academic, small and large industrial, and the general public in industrialized nations) are either developing or using engineered nanomaterials (ENMs) or ENM-containing products. However, our understanding of the occupational, health and safety aspects of ENMs is still in its formative stage. A survey of the literature indicates the available information is incomplete, many of the early findings have not been independently verified, and some may have been over-interpreted. This review describes ENMs briefly, their application, the ENM workforce, the major routes of human exposure, some examples of uptake and adverse effects, what little has been reported on occupational exposure assessment, and approaches to minimize exposure and health hazards. These latter approaches include engineering controls such as fume hoods and personal protective equipment. Results showing the effectiveness - or lack thereof - of some of these controls are also included. This review is presented in the context of the Risk Assessment/Risk Management framework, as a paradigm to systematically work through issues regarding human health hazards of ENMs. Examples are discussed of current knowledge of nanoscale materials for each component of the Risk Assessment/Risk Management framework. Given the notable lack of information, current recommendations to minimize exposure and hazards are largely based on common sense, knowledge by analogy to ultrafine material toxicity, and general health and safety recommendations. This review may serve as an overview for health and safety personnel, management, and ENM workers to establish and maintain a safe work environment. Small start-up companies and research institutions with limited personnel or expertise in nanotechnology health and safety issues may find this review particularly useful.
\end{abstract}

\section{Introduction}

\section{A. The objectives of this review}

Although there has been considerable work to advance nanotechnology and its applications, understanding the occupational, health and safety aspects of engineered nanomaterials (ENMs) is still in its formative stage. The goals of this review are to describe some general features of ENMs, how a worker might be exposed to ENMs, some potential health effects, and approaches to minimize exposure and toxicity. The target audience includes industrial hygienists, investigators working with these materials, institutes and universities conducting research, and start-up companies that may not have the

\footnotetext{
* Correspondence: ryokel@email.uky.edu

'Department of Pharmaceutical Sciences, College of Pharmacy and Graduate Center for Toxicology, University of Kentucky, Lexington, KY, 40536-0082, USA

Full list of author information is available at the end of the article
}

necessary occupational health and safety expertise, knowledge, and/or staff.

A comprehensive review described the field of nanotoxicology six years ago, including some mechanisms of toxicity, portals of ENM entry, their translocation, and the state of their risk assessment at the time [1]. More recent reviews have focused on the major challenges, key questions, and research needs to assess ENM toxicity and risk [2-7]. This review addresses issues not extensively covered in prior reviews, including recent exposure-assessment studies, and engineering and personal protective equipment (PPE) options and their efficacy to minimize ENM exposure. This review also includes accepted but not yet published reports, recently completed studies not yet published, and ongoing work. Our goal was to provide up-to-date information on ENM exposures, their health hazards, and ways to minimize risk.

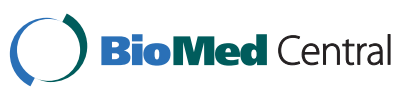

() 2011 Yokel and MacPhail; licensee BioMed Central Ltd. This is an Open Access article distributed under the terms of the Creative Commons Attribution License (http://creativecommons.org/licenses/by/2.0), which permits unrestricted use, distribution, and reproduction in any medium, provided the original work is properly cited. 


\section{B. Engineered nanomaterials}

Nano is a prefix derived from the Greek word for dwarf. The parts of the U. S. National Nanotechnology Initiative (NNI) definition that are relevant for this review define nanoscale materials as having at least one dimension in the range of 1 to 100 nanometers (nm), with properties that are often unique due to their dimensions, and that are intentionally manufactured [8]. There are many definitions of nanoscale materials, which generally encompass the same bounds on ENM size $[9,10]$. This is in contrast to naturally occurring and unintentionally-produced materials on the same scale, which are referred to as ultrafine particles. The term ultrafine has been used by the aerosol research and occupational and environmental health communities to describe airborne particles smaller than $100 \mathrm{~nm}$ in diameter [11]. Ultrafine particles are not intentionally produced. They are the products of combustion and vaporization processes such as welding, smelting, fuel combustion, fires, and volcanoes $[1,12,13]$. In this review, intentionally-manufactured nanoscale materials will be referred to as ENMs. They are usually produced by bottom-up processes, such as physical and chemical vapor deposition, liquid phase synthesis, and self-assembly [5,14].

The health and environmental effects of ENMs are not well understood, leading some to caution development of this technology [15-19]. Some understanding of ENM effects can be derived, however, by analogy from ultrafine particles, which have been shown to produce inflammation, exacerbation of asthma, genotoxicity, and carcinogenesis following inhalation. The following sections describe ENMs, and some of their uses and uncertainties, providing the context of this review.

\section{Common ENM size, composition, and quality}

Figure 1 relates ENM size to other chemical and biological materials. There are a staggering number of ENM compositions and shapes. Over 5000 patents have been issued for carbon nanotubes (CNTs) and > 50,000 varieties of CNTs have been produced [20]. The sheer number of ENMs contributes to the lack of our adequate understanding of ENM health and safety. They are primarily composed of carbon or metal/metal oxide, as illustrated by the representative manufactured nanomaterials selected for testing by the Organisation for Economic Co-operation and Development (OECD) [21]. Carbon-based ENMs include single-walled and multiwalled carbon nanotubes (SWCNTs and MWCNTs), graphene (a single sheet of carbon atoms in a hexagonal structure), spherical fullerenes (closed cage structures composed of 20 to 80 carbon atoms consisting entirely of three-coordinate carbon atoms, e.g., $\mathrm{C}_{60}$ [Buckyballs, buckminsterfullerene]), and dendrimers, which are symmetrical and branched. SWCNTs and MWCNTs are $\sim 1$ to 2 and 2 to $50 \mathrm{~nm}$ wide, respectively, and can be $>1$ $\mu \mathrm{m}$ long. The $\mathrm{C}_{60}$ diameter is $\sim 1 \mathrm{~nm}$. Metal and metal oxide ENMs most commonly studied are cadmium in various complexes, gallium arsenide, gold, nickel, platinum, silver, aluminum oxide (alumina), cerium dioxide (ceria), silicon dioxide (silica), titanium dioxide $\left(\mathrm{TiO}_{2}\right.$, titania), and zinc oxide. The size of ENMs is in the same range as major cellular machines and their components, such as enzymes, making it likely that they will easily interact with biochemical functions [22].

Some ENMs contain contaminants, such as residual metal catalysts used in the synthesis of CNTs. ENM toxicity has been attributed to these residual metals, as discussed in II, B, 1. ENM exposure effects in the lung. The physico-chemical properties of ENMs, when tested prior to their use, are often different from those stated by the supplier $[23,24]$. A major cause of changes in the physico-chemical properties of ENMs over time and in various media is agglomeration, discussed in II, A, 2. The physico-chemical properties of ENMs that impact their uptake. When ENMs are not sufficiently characterized to identify their composition or properties it makes the prediction of toxicity, when added to the insufficient understanding of their biological effects, even more difficult [25].

\section{Some uses of ENMs and the projected market and workforce}

There is considerable interest in developing ENMs because their properties differ in fundamental and valuable ways from those of individual atoms, molecules, and bulk matter. Nanoscale products and materials are increasingly being used in optoelectronic, electronic (e. g., computer hard drives), magnetic, medical imaging, drug delivery, cosmetic and sunscreen, catalytic, stain resistant fabric, dental bonding, corrosion-resistance, and coating applications [26]. Major future applications are expected to be in motor vehicles, electronics, personal care products and cosmetics, and household and home improvement. These applications capitalize on their electromagnetic, catalytic, pharmacokinetic, and physico-chemical properties, including strength, stiffness, weight reduction, stability, anti-fogging, and scratch resistance. Current products contain various ENMs including nanotubes, metal oxides, and quantum dots (semiconductors developed as bright, photostable fluorescent dyes and imaging agents). Nanowerk identified 2500 commercial nanomaterials, including 27\% metal oxides, $24 \%$ CNTs, $18 \%$ elements, $7 \%$ quantum dots, and 5\% fullerenes [http://www.nanowerk.com/ phpscripts/n_dbsearch.php]. There are $>1000$ consumer products available that contain ENMs. They are primarily composed of silver, carbon, zinc, silica, titania and gold. The main application is in health and fitness 


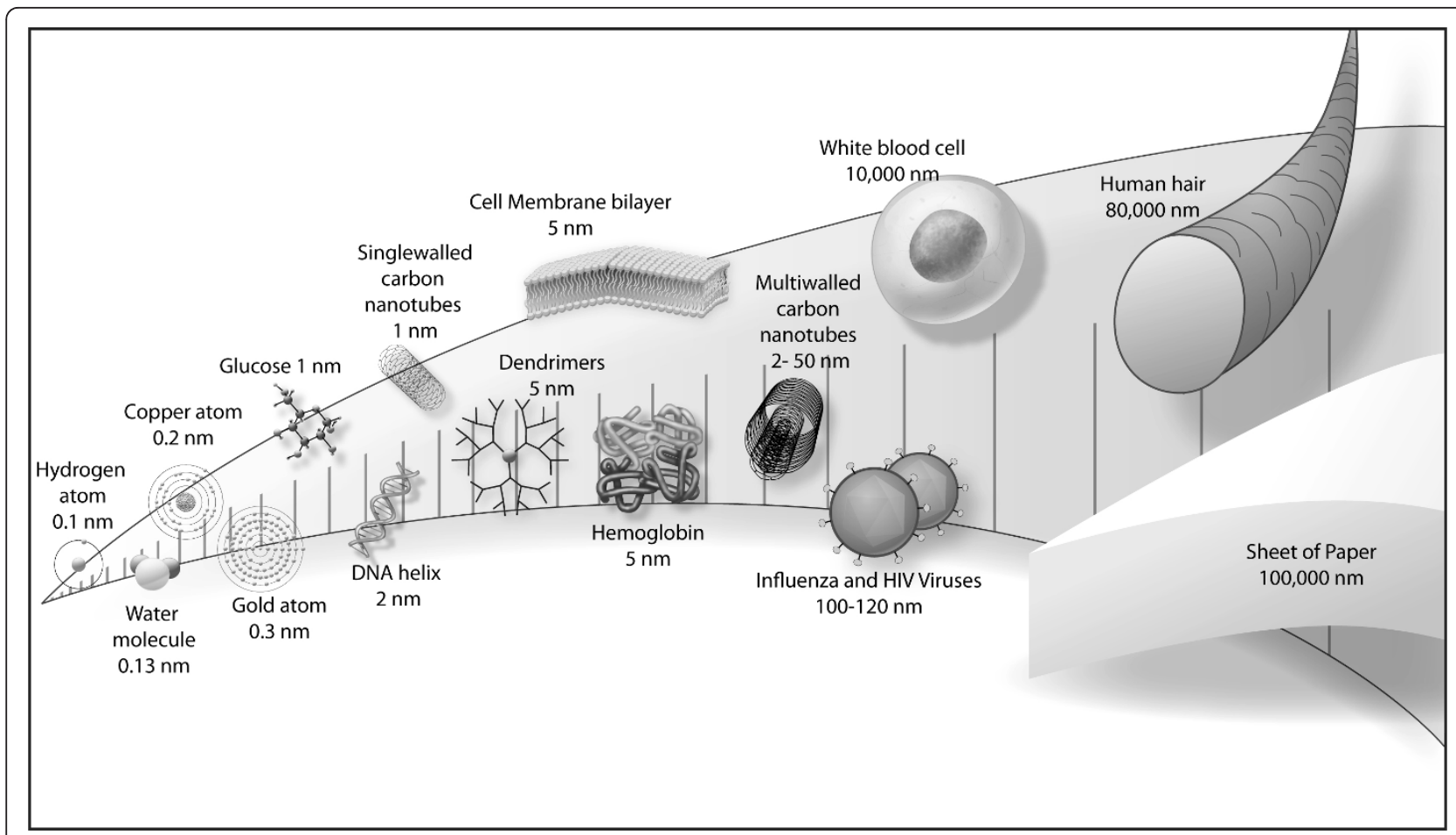

Figure 1 The sizes and shapes of some ENMs compared to more familiar materials. Shown for comparison are materials that are below, within, and above the nanoscale range, to put ENM size in perspective.

products $[27,28]$. Three to four new nanotechnologycontaining consumer products are introduced weekly into the market, according to The Project on Emerging Nanotechnologies [http://www.nanotechproject.org/ inventories/consumer/].

The anticipated benefits of ENM applications resulted in expenditure of $\$ 18$ billion worldwide on nanotechnology research and development in 2008. In 2004 Lux Research predicted that nanotechnology applications will become commonplace in manufactured goods starting in 2010 and become incorporated into 15\% of global manufacturing output in 2014 [https://portal.luxresearchinc.com/research/document_excerpt/2650]. The ENM workforce is estimated to grow $\sim 15 \%$ annually [29]. An epidemiological feasibility study of CNT workers initiated in 2008 revealed most manufacturers were small companies that had no environmental/occupational health and safety person and little knowledge about this topic [30]. By 2015, the global market for nanotechnology-related products is predicted to employ 2 million workers (at least 800,000 in the U.S.) to support nanotechnology manufacturing, and $\$ 1$ trillion in sales of nanotechnology-related products [31].

\section{E. Uncertainties regarding the adverse effects of ENMs}

There have been concerns about the safety and public acceptance of this burgeoning technology, particularly in the past 5 years, due to the lack of much information about potential adverse effects [32]. This resulted in an increase from 2.9 to $6.6 \%$ of the NNI budget for environmental health and safety from 2005 to 2011. Prior to 2005 it does not seem funds were specifically allocated for this purpose nor was the U.S. National Institute for Occupational Safety and Health (NIOSH) a contributor to NNI funding $[33,34]$. The United Nations Educational, Scientific and Cultural Organization (UNESCO) compared the concerns of the public over new products with their perception of genetically modified foods/ organisms to nanotechnology. They noted that the lack of knowledge can result in restrictions, outright bans, and international conflicts over production, sale, and transport of such materials [35]. Public acceptance can influence the success of an emergent technology, as public opinion is considerably influenced by information prior to the adoption of the technology. However, individuals form opinions often when they do not possess much information, based on factors other than factual information, including values, trust in science, and arguments that typically lack factual content [36]. This creates a challenge to earn public acceptance of nanotechnology.

There is a notable lack of documented cases and research of human toxicity from ENM exposure. It is widely recognized that little is known about ENM safety. 
An uncertainty analysis revealed knowledge gaps pervade nearly all aspects of ENM environmental health and safety [4]. Owing to their small size and large surface area, ENMs may have chemical, physical, and biological properties distinctly different from, and produce effects distinct from or of a different magnitude than, fine particles of similar chemical composition. This is discussed in II, A, 2. The physico-chemical properties of ENMs that impact their uptake. ENM properties often differ from individual atoms, molecules, and from bulk matter. These differences include a high rate of pulmonary deposition, the ability to travel from the lung to systemic sites, and a high inflammatory potential [1]. Further contributing to our lack of understanding of the potential health effects of ENMs is that most production is still small scale. As such, potential adverse effects from the anticipated increase in large scale production and marketing of ENM-containing products and use are generally unknown. Furthermore, the number of novel ENMs being created continues to grow at a high rate, illustrated by the accelerating rate of nanotechnologyrelated patent applications $[37,38]$.

\section{A Framework for Evaluating the Risk of ENMs}

We elected to review the existing literature on ENM effects in the context of the Risk Assessment/Risk Management framework as originally described in the U.S. National Research Council report "Risk Assessment in the Federal Government: Managing the Process", often called the Red Book, that mainly dealt with chemical threats to health [39]. The framework is depicted in Figure 2. A similar approach was advanced by the European Chemicals Bureau for biocidal products (http:// eur-lex.europa.eu/pri/en/oj/dat/2003/1_307/

1_30720031124en00010096.pdf). Although the NRC framework is portrayed as a sequential approach, in practice it is dynamic with considerable interaction between risk assessors, scientists, and often times the affected parties. This general approach has been proposed for evaluating the risks of ENMs [5-7]. A notable alternative is the Nano Risk framework, a joint venture of the Environmental Defense Fund and DuPont [40]. In addition, due to the many different ENMs, and the time and cost to thoroughly assess their potential risks [41], there is currently much interest in developing in vitro models that are predictive of in vivo effects [42], although these are not always successful [42-44], and in developing tiered testing systems $[45,46]$. Additional efforts are underway to group (band) similar ENMs in order to promote safe handling and use of ENMs, and restrict worker exposure, in the absence of definitive health and safety information $[47,48]$. Still others are applying computational approaches to predict ENM effects, including toxicity $[49,50]$.

In this review the Risk Assessment/Risk Management framework will be used as a template because it succinctly codifies the diverse practices of risk assessment into a logical framework that collects data to determine

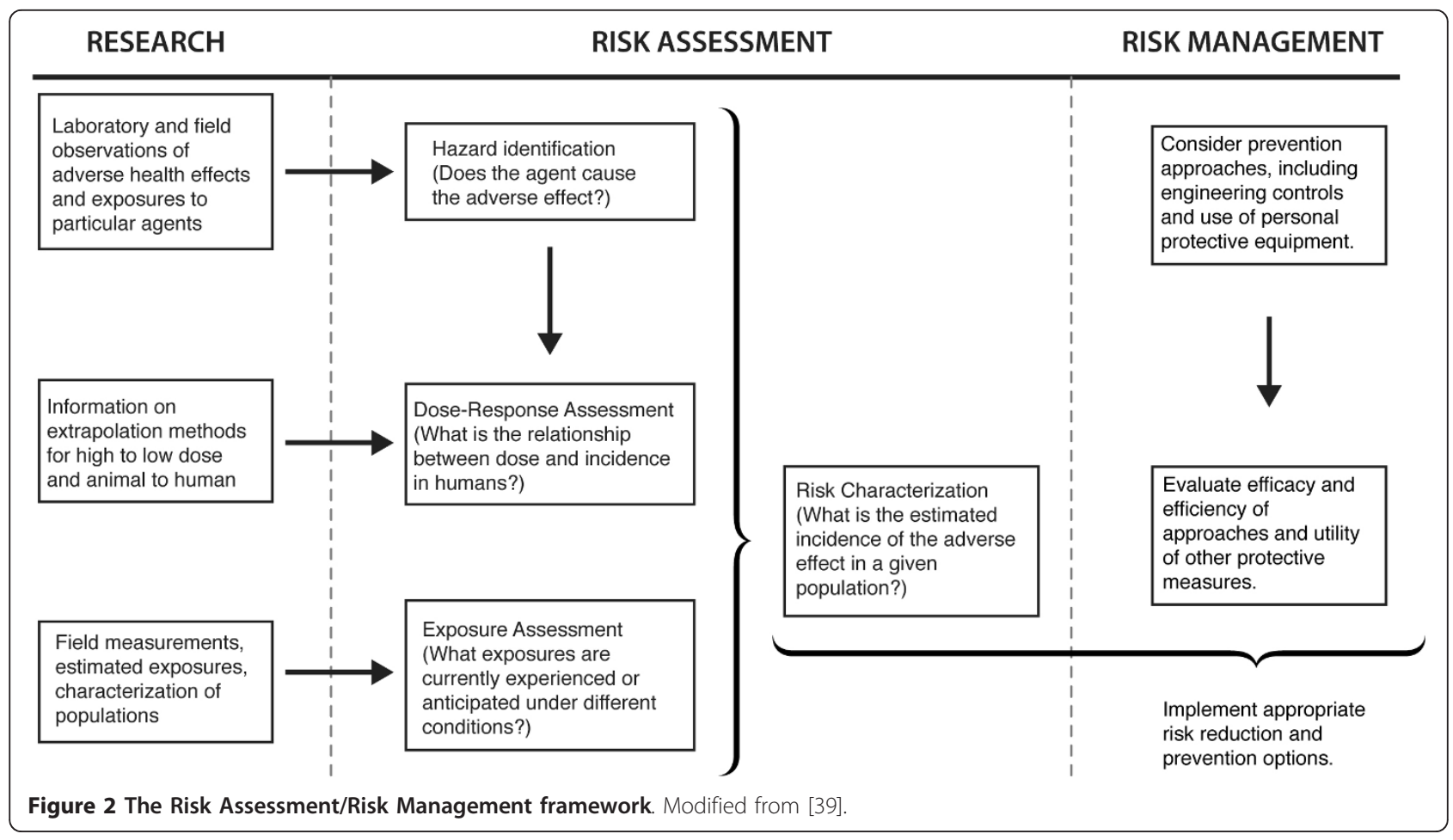


(1) whether an agent causes an adverse effect, (2) how the effect is related to dose, (3) whether exposure is likely, and (4) the probability of adverse effects in the population at current exposure levels. The framework also embraces research that feeds each of the elements of the risk assessment with the necessary information. For the current review, this framework provides a systematic method to work through the many issues surrounding the potential health effects of ENMs.

The first element, hazard identification, addresses whether there is any evidence that an agent causes an adverse effect. Hazard identification represents the lowest hurdle in the process, since the evidence could come from any number of sources, including laboratory or field observations, and might only be suggestive. The next element, dose-response assessment, is more rigorous and asks whether there is a relationship between the dose of the agent and the incidence or magnitude of adverse effect. This element is based on the fundamental tenet in toxicology and pharmacology of dose response; that is, as the dose increases so does the effect. This information is often not directly available for humans, so laboratory animal studies are typically used. Exposure assessment is the next element. If evidence indicates an agent poses a hazard, and the hazard is dose-related, the next step is to determine the extent of occupational or daily life exposure. Information from all elements is then combined into a risk characterization, which estimates the likelihood of an adverse effect occurring in the exposed population or a segment of the population.

The Risk Assessment/Risk Management framework is comprised of 3 essential components; research, risk assessment, and risk management. Risk assessment is regarded as a scientific undertaking whereas risk management uses the science to regulate exposure to the agent in ways that take into account social benefits, economic costs, and legal precedents for action.

The following sections are arranged to follow the NRC paradigm. Examples are given of adverse effects of ENMs to show why there may be reason for concern. Reports on exposure levels, the likelihood of adverse effects resulting from exposure, and options for minimizing risk are also summarized. This is not, however, an all-inclusive review of the literature; interested readers are referred to the reference section for a number of comprehensive reviews of many of the topics pertaining to ENMs and their effects.

\section{A. Hazard identification}

In the occupational context, hazard identification can be re-stated as "What effects do ENMs have on workers' health?" to which NIOSH has stated: "No conclusive data on engineered nanoparticles exist for answering that question, yet. Workers within nanotechnology- related industries have the potential to be exposed to uniquely engineered materials with novel sizes, shapes, and chemical properties, at levels far exceeding ambient concentrations...much research is still needed." [http:// www.cdc.gov/niosh/topics/nanotech/about.html].

Information about ENMs might be obtained from well-documented retrospective analyses of unintended exposures. The most extensive exposures to ENMs likely occur in the workplace, particularly research laboratories; start-up companies; pilot production facilities; and operations where ENMs are processed, used, disposed, or recycled [51]. Occupational hygienists can contribute to the knowledge and understanding of ENM safety and health effects by thorough documentation of exposures and effects. In the U.S., NIOSH is responsible for conducting research and making recommendations for the prevention of work-related illnesses and injuries, including ENMs. The U.S. Occupational Safety and Health Administration (OSHA) is responsible for making and enforcing the regulations.

\section{The key routes of ENM exposure}

Figure 3 illustrates the four routes that are most likely to result in ENM exposure of the five organ systems which are the major portals of ENM entry: skin, gastrointestinal tract, lung, nasal cavity, and eyes [22]. It also illustrates the most likely paths of translocation (re-distribution or migration), enabling ENMs to reach organs distal to the site of uptake.

The inhalation route has been of greatest concern and the most studied, because it is the most common route of exposure to airborne particles in the workplace. The skin has also been investigated. Most studies have shown little to no transdermal ENM absorption. Oral (gastrointestinal) exposure can occur from intentional ingestion, unintentional hand-to-mouth transfer, from inhaled particles $>5 \mu \mathrm{m}$ that are cleared via the mucociliary escalator, and of drainage from the eye socket via the nasal cavity following ocular exposure. Direct uptake of nanoscale materials from the nasal cavity into the brain via the olfactory and trigeminal nerves has been shown. Each of these routes is discussed in more detail below.

Routes that avoid first-pass clearance and metabolism in the gastrointestinal tract and liver include uptake (absorption) from the nasal cavity (either into systemic circulation or directly into the brain), orotransmucosal (e.g., buccal [from the cheek] and sub-lingual), and transdermal. These routes may present a greater risk of ENM-induced adverse effects because more ENM is likely to reach the target organ(s) of toxicity.

\section{The physico-chemical properties of ENMs that impact their uptake}

Hazard identification has revealed that the physico-chemical properties of ENMs can greatly influence their 


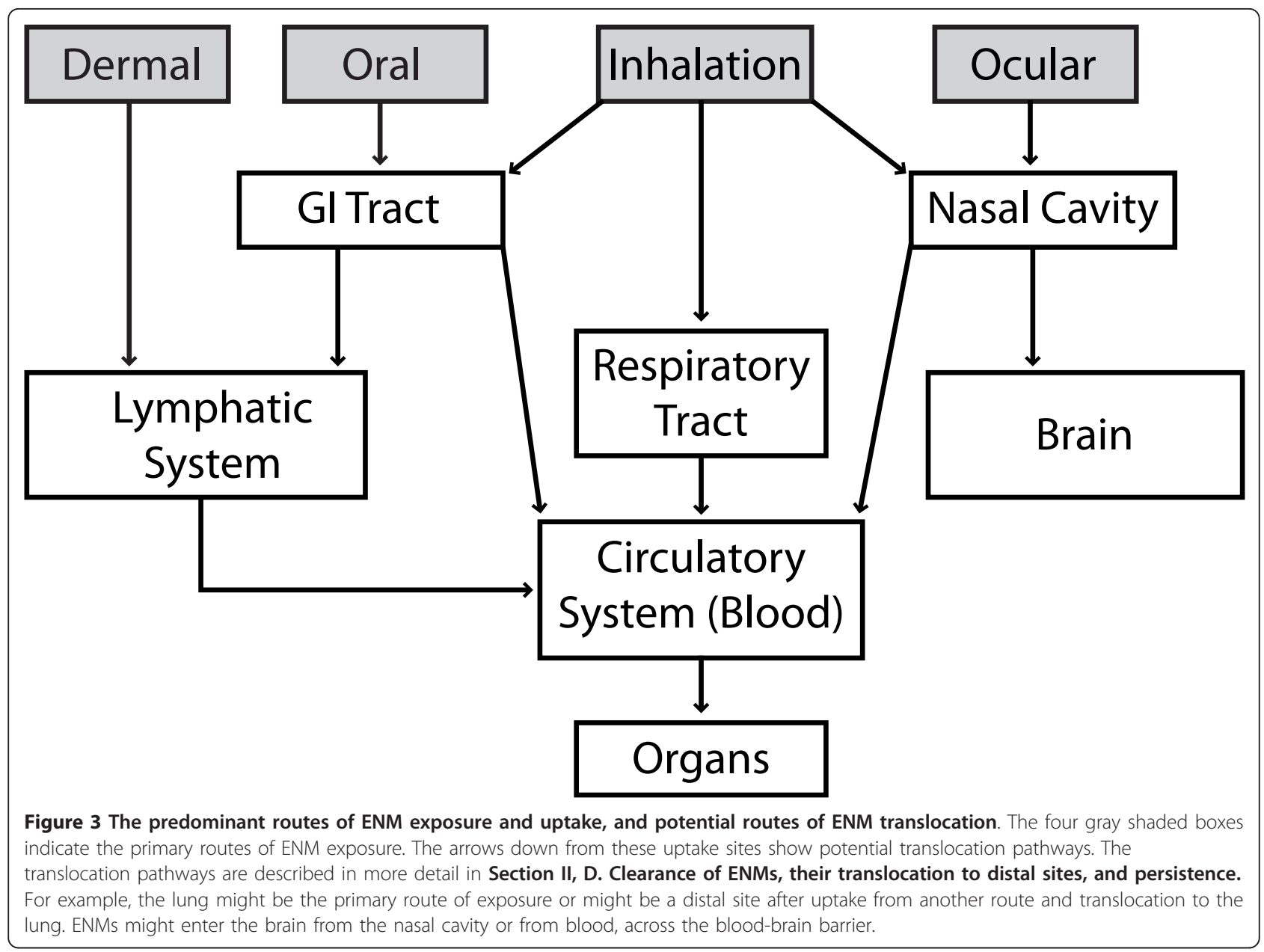

uptake. ENMs show greater uptake and are more biologically active than larger-sized particles of the same chemistry, due to their greater surface area per mass $[52,53]$. Additional ENM characteristics that may influence their toxicity include size, shape, surface functionalization or coating, solubility, surface reactivity (ability to generate reactive oxidant species), association with biological proteins (opsonization), binding to receptors, and, importantly, their strong tendency to agglomerate. An agglomeration is a collection of particles that are loosely bound together by relatively weak forces, including van der Waals forces, electrostatic forces, simple physical entanglement, and surface tension, with a resulting external surface area similar to the sum of the surface area of the individual components $[9,54]$. Agglomeration is different from aggregation. Aggregated particles are a cohesive mass consisting of particulate subunits tightly bound by covalent or metallic bonds due to a surface reconstruction, often through melting or annealing on surface impact, and often having an external surface area significantly smaller than the sum of calculated surface areas of the individual components
[9,54]. Agglomerates may be reversible under certain chemical/biological conditions whereas an aggregate will not release primary particles under normal circumstances of use or handling. Airborne ENMs behave very much like gas particles. They agglomerate in air due to self-association (in one study increasing from 8 to 15 $\mathrm{nm}$ in $16 \mathrm{~min}$ and to $100 \mathrm{~nm}$ in $192 \mathrm{~min}$ ) and interaction with background aerosols (to $\sim 500 \mathrm{~nm}$ agglomerates within min) [55]. Studies of ENMs in occupational settings showed airborne particulates were most commonly 200 to 400 and 2000 to $3000 \mathrm{~nm}[51,56]$. ENMs also agglomerate in liquids, resulting in micrometer sized particles [57]. One study showed that concentration and smaller ENM size positively correlated with speed of agglomeration [58]. Changes in ENM surface area can profoundly uptake and effects.

The aspect ratio (length:diameter) of ENMs also plays a major role in their toxic potential. Particles with a length > $5 \mu \mathrm{m}$ and aspect ratio $\geq 3: 1$ are conventionally defined as fibers [59]. Inhaled asbestos containing high aspect-ratio fibers is more toxic than lower aspect-ratio fibers. Foreign materials are often cleared by macrophage phagocytosis, 
but when too large to be phagocytosed they are not effectively cleared from the lung. This results in release of inflammatory mediators, discussed below.

It appears that $\sim 15$ to $30 \mathrm{~nm}$ is a critical width or diameter for ENMs to have properties different from the solution and bulk chemistry of their components. Reactive oxygen species generation in an acellular system to which 4 to $195 \mathrm{~nm}$ titania ENMs were added was negligible up to $10 \mathrm{~nm}$, then increased up to $\sim 30 \mathrm{~nm}$, when it reached a plateau [53]. A review concluded there is a critical size for ENMs at which new properties typically appear. These new properties are strongly related to the exponential increase in the number of atoms localized at the surface, making metal and metal oxide ENMs with diameters $<20$ to $30 \mathrm{~nm}$ most different from bulk material [60]. For example, 1 and $3 \mathrm{~nm}$ gold ENMs, which contain $\sim 30$ and 850 atoms, have nearly all and $\sim 50 \%$ of their atoms surface exposed, respectively. Additionally, the optimal particle radius to accelerate adhesion to a cell-surface lipid bilayer is 15 and $30 \mathrm{~nm}$ for cylindrical and spherical particles, respectively [61,62]. Therefore, 10 to $30 \mathrm{~nm}$ diameter ENMs that have a spherical or similar shape appear to have the potential for more profound biological effects than either smaller or larger ENMs.

It is prudent to apply the continually improving understanding of the influence of the physico-chemical properties of ENMs on their effects and safety to the development of future ENMs, to enhance their benefit/ risk ratio. Second generation (active) ENMs are being developed, such as targeted control-release systems for drugs. There is utility in the use of CNTs as drug delivery systems. Based on the studies of the role of CNT physico-chemical properties in biological effects it has been concluded that the use of low aspect ratio (length $\leq 1 \mu \mathrm{m}$ ), high purity (97-99\%), low metal catalyst content CNTs minimizes cytotoxicity and provides apparent in vivo bio-compatibility [63]. Application of the continued understanding of the influence of physico-chemical properties on biological responses can similarly enhance the benefit/risk ratio of future ENMs, such as: application of the most predictive dose metric; the rate and nature of interacting proteins and effect of opsonization on uptake, translocation and effects; the influence of size, shape, charge, and surface reactivity on the extent and sites of translocation; and the duration of persistence of ENMs in organs and associated effects. Additionally, observations of workers exposed to ENMs can greatly add to this understanding, to increase confidence in the predicted effects of future ENMs.

\section{a. The role of surface coating in ENM uptake and effects}

ENMs are rapidly coated in biological milieu, primarily by proteins [62,64-66]. Due to high energetic adhesive forces close to the surface, ENMs can agglomerate and adsorb to the next available surface and other small molecules [67]. Extensive addition of polyethylene glycol (PEG) to the surface of SWCNTs has been shown to favor uptake into tumors compared to normal organs [68]. Similarly, addition of PEG to poly(di-lactic acid-comalic acid) coated magnetic ENMs enhanced their uptake by macrophages [69]. Commercial providers and researchers often add a surface coating to inhibit ENM agglomeration and/or influence their uptake and cellular effects [70]. Cells that line the airways produce mucus. Pulmonary type II alveolar cells secrete surfactants (a mixture of $90 \%$ phospholipids and lung surfactant-specific proteins). Lung surfactants incorporate ENMs [71,72]. Mucus, which is secreted by goblet cells in the respiratory tract, eye, nasal cavity, stomach, and intestine, entraps ENMs [65]. All of these surface coatings on ENMs would be expected to affect their uptake and effects.

\section{b. ENM uptake from the initial sites of exposure}

To understand ENM-induced effects and their mechanisms of action, cells in culture and other in vitro systems have been utilized. However, these systems cannot model the complexities of the entire organism, including the limitation of uptake provided by such barriers as the skin and first-pass metabolism, opsonization, metabolism that may inactivate or activate a substrate, translocation to distal sites, activation of homeostatic defenses, or inflammatory processes that release cytokines and other factors that can act at distant sites from their release. Therefore, this review primarily cites examples of whole-animal studies to address ENM uptake and translocation.

i). Lungs There has been much interest in the health effects of airborne particles, specifically $\mathrm{PM}_{10}$ (thoracic fraction), $\mathrm{PM}_{2.5}$ (respirable fraction), $\mathrm{PM}_{1}$, and ultrafine particles $\left(\mathrm{PM}_{0.1}\right)$, which are $\leq 10,2.5,1$ and $0.1 \mu \mathrm{m}(100$ $\mathrm{nm})$, respectively. One- to 5-nm air-suspended ENMs that enter the lungs are not predicted to reach the alveoli; instead a high percentage is likely to deposit in the mucus-lined upper airways (tracheo-bronchial region) due to their strong diffusion properties. On the other hand $\sim 45 \%$ of $10-\mathrm{nm}, \sim 50 \%$ of $20-\mathrm{nm}$, and $\sim 25 \%$ of 100-nm ENMs deposit in the alveoli [73]. Deposition is greater during exercise. Chronic obstructive pulmonary disease increases tracheo-broncheolar and decreases alveolar particle deposition [74,75].

ii) Nasal cavity Uptake from the nasal cavity into the olfactory nerve, followed by retrograde axonal transport to the olfactory bulb and beyond, was shown in studies of the polio virus $(30 \mathrm{~nm})$ and colloidal silver-coated gold $(50 \mathrm{~nm})$ [76-78]. Uptake of $\sim 35-\mathrm{nm}{ }^{13} \mathrm{C}$ particles along the olfactory pathway to the olfactory bulb, and to a lesser extent into the cerebrum and cerebellum, was shown 1 to 7 days later [79]. Exposure to $\sim 30 \mathrm{~nm}$ 
agglomerates of $\mathrm{Mn}$ by inhalation resulted in up to a 3.5-fold increase of $\mathrm{Mn}$ in the olfactory bulb, and lower (but significant) increases in 4 rat brain regions. The increase of $\mathrm{Mn}$ in brain regions other than the olfactory bulb may have resulted from translocation to the brain by route(s) other than via the olfactory nerve, such as through cerebrospinal fluid or across the blood-brain barrier [80]. The nasal cavity is the only site where the nervous system is exposed directly to the environment. This is an often overlooked potential route of uptake of small amounts of ENMs into the brain.

iii.) Dermal exposure Skin is composed of 3 primary layers, the outermost epidermis (which contains the stratum corneum, stratum granulosum and stratum spinosum), dermis, and hypodermis. The hair follicle is an invagination of the stratum corneum, lined by a horny layer (acroinfundibulum). Dermal uptake routes are intercellular, intracellular, and follicular penetration. Uptake is primarily by diffusion. Materials that diffuse through the lipid-rich intercellular space of the stratum corneum typically have a low molecular weight $(<500$ $\mathrm{Da})$ and are lipophilic. Materials that penetrate the stratum corneum into the stratum granulosum can induce the resident keratinocytes to release pro-inflammatory cytokines. Materials that penetrate to the stratum spinosum, which contains Langerhans cells (dendritic cells of the immune system), can initiate an immunological response. This is mediated by the Langerhans cells, which can become antigen-presenting cells and can interact with T-cells. Once materials reach the stratum granulosum or stratum spinosum there is little barrier to absorption into the circulatory and lymphatic systems. Whereas dry powder ENMs pose a greater risk for inhalation exposure than those in liquids, liquid dispersed ENMs present a greater risk for dermal exposure.

Consumer materials most relevant to dermal exposure include quantum dots, titania, and zinc oxide in sunscreens, and silver as an anti-microbial agent in clothing and other products. Prolonged dermal application of microfine titania sunscreen suggested penetration into the epidermis and dermis [81]. However, subsequent studies did not verify penetration of titania from sunscreens into the epidermis or dermis of human, porcine or psoriatic skin [82-87], or find evidence of skin penetration of zinc oxide from sunscreen or positively- or negatively-charged iron-containing ENMs [88,89]. Nanoparticles with a dye penetrated deeper into hair follicles of massaged porcine skin in vitro and persisted longer in human skin in vivo than the dye in solution $[82,90,91]$. Thirty-nm carboxylated quantum dots applied to the skin of mice were localized in the folds and defects in the stratum corneum and hair follicles. A small amount penetrated as deep as the dermis. Ultraviolet radiation increased penetration, raising concern that these results might generalize to nanoscale sunscreens [92]. PEG-coated $\sim 37 \mathrm{~nm}$ quantum dots accumulated in the lymphatic duct system after intra-dermal injection in mice. Cadmium, determined by ICP-MS, from cadmium-containing quantum dots was seen in liver, spleen, and heart; however, it is uncertain if this was from dissolved cadmium or translocation of the quantum dots because methods were not used to show the presence of quantum dots. The above results suggest topically-applied ENMs that penetrate to the dermis might enter the lymphatic system, and the ENMs or dissolved components distribute systemically [93]. To address these concerns ENMs intended for dermal application, such as titania, are often surface coated, e.g. with silica, alumina, or manganese. One goal of the surface treatments is to minimize toxicity by trapping the free radicals of reactive oxygen species (ROS) [94].

An in vitro study showed that mechanical stretching of human skin increased penetration of 500 and 1000 $\mathrm{nm}$ fluorescent dextran particles through the stratum corneum, with some distribution into the epidermis and dermis [95]. Similarly, mechanical flexing increased penetration of a $3.5 \mathrm{~nm}$ phenylalanine-based $\mathrm{C}_{60}$ amino acid ENM through porcine skin in vitro [96]. The contribution of skin flexing and immune system response was further addressed with three titania formulations applied to minipigs. There was some ENM penetration into epidermis and abdominal and neck dermis, but no elevation of titanium in lymph nodes or liver [97]. Topical exposure of mice to SWCNTs resulted in oxidative stress in the skin and skin thickening, demonstrating the potential for toxicity not revealed by in vitro studies of ENM skin penetration [98]. There are no reports of long-term studies with topical ENM exposure.

In the absence of organic solvents, the above suggests that topically applied ENMs do not penetrate normal skin. Not surprisingly, organic solvents (chloroform > cyclohexane $>$ toluene) increased penetration of fullerene into skin that had the stratum corneum removed by tape stripping [99]. As the fullerenes were not detected in systemic circulation, there was no evidence of systemic absorption.

iv.) Oral exposure Little is known about the bioavailability of ENMs from the buccal cavity or the sub-lingual site, or possible adverse effects from oral ingestion.

Particle absorption from the intestine results from diffusion though the mucus layer, initial contact with enterocytes or M (microfold or membranous specialized phagocytic enterocyte) cells, cellular trafficking, and post-translocation events [100]. Colloidal bismuth subcitrate particles $(4.5 \mathrm{~nm}$ at neutral $\mathrm{pH})$ rapidly penetrated the mucosa of dyspeptic humans, resulting in bismuth in the blood. Particles appeared to penetrate only in regions of gastric epithelial disruption [101]. Greater 
uptake of 50 to $60 \mathrm{~nm}$ polystyrene particles was seen through Peyer's patches and enterocytes in the villous region of the GI tract than in non-lymphoid tissue, although the latter has a much larger intestinal surface area [102,103]. Peyer's patches are one element of gutassociated lymphoid tissue, which consist of $\mathrm{M}$ cells and epithelial cells with a reduced number of goblet cells, resulting in lower mucin production $[100,103]$. It was estimated that $\sim 7 \%$ of $50-\mathrm{nm}$ and $4 \%$ of $100-\mathrm{nm}$ polystyrene ENMs were absorbed [104]. Fifty-nm polystyrene ENMs fed to rats for 10 days by gavage showed $34 \%$ absorption, of which about $7 \%$ was in the liver, spleen, blood, and bone marrow; no ENMs were seen in heart or lung [104]. After oral administration of 50-nm fluorescence-labeled polystyrene ENMs, $18 \%$ of the dose appeared in the bile within $24 \mathrm{~h}$ and $9 \%$ was seen in the blood at $24 \mathrm{~h}$; none was observed in urine [105]. The mechanism of GI uptake of 4, 10, 28 or $58 \mathrm{~nm}$ colloidal (maltodextran) gold ENMs from the drinking water of mice was shown to be penetration through gaps created by enterocytes that had died and were being extruded from the villus. Gold abundance in peripheral organs inversely correlated with particle size [106].

In summary, there appears to be significant absorption of some ENMs from the GI tract, with absorption inversely related to ENM size. The absorption site seems to be regions of compromised gastric epithelial integrity and low mucin content.

v.) Ocular and mucous membrane exposure Ocular exposure might occur from ENMs that are airborne, intentionally placed near the eye (e.g., cosmetics), accidently splashed onto the eye, or by transfer from the hands during rubbing of the eyes, which was shown to occur in $37 \%$ of 124 adults every hour [107]. This route of exposure could result in ENM uptake through the cornea into the eye or drainage from the eye socket into the nasal cavity through the nasolacrimal duct. Other than a study that found uptake of a polymer ENM into conjunctival and corneal cells, this route has been largely ignored in research studies of ENM exposure [108].

\section{B. The effects of ENM exposure on target organs and those distal to the site of uptake}

Public concerns about ENMs and health may arise with reports of some effect(s) in a laboratory study or their presence in human tissue (or another organism). Any report must be interpreted carefully before concluding ENMs are risky for one's health. To start with, risk is defined as a joint function of a chemical's ability to produce an adverse effect and the likelihood (or level) of exposure to that chemical. In a sense, this is simply a restatement of the principle of dose-response; for all chemicals there must be a sufficient dose for a response to occur. Additionally, advances in analytical chemistry have led to highly sensitive techniques that can detect chemicals at remarkably low levels (e.g., in parts per billion or parts per trillion). The detectable level may be far lower than any dose shown to produce an adverse effect. Further, a single finding in the literature may garner public attention, and it may be statistically significant, but its scientific importance remains uncertain until it is replicated, preferably in another laboratory. In this regard, a follow-up study may be warranted to characterize the relevant parameters of dose, duration, and route of exposure, as outlined in the Risk Assessment/ Risk Management framework.

The above discussion reflects many of the issues that have gained prominence in the fields of risk perception and risk communication (see for example $[109,110]$ ), neither of which were dealt with by the NRC in their landmark publication.

The knowledge of ultrafine-particle health effects has been applied to ENMs. However, the toxicity from ultrafine materials and ENMs is not always the same [111]. Similarly, the effects produced by ENM components do not reliably predict ENM effects. For example, toxicity was greater from cadmium-containing quantum dots than the free cadmium ion [112]. Some metal and metal oxide ENMs are quite soluble (e.g., $\mathrm{ZnO}$ ), releasing metal ions that have been shown to produce many of the effects seen from ENM exposure [113,114]. Therefore, one cannot always predict ENM toxicity from the known effects of the bulk or solution ENM components.

\section{ENM exposure effects in the lung}

Studies of ENM inhalation and intratracheal instillation as well as with lung-derived cells in culture have increased concern about potential adverse health effects of ENMs. An early 2-year inhalation study of Degussa P-25 (a $\sim 3: 1$ mixture of $\sim 85-\mathrm{nm}$ anatase and $25-\mathrm{nm}$ rutile titania) resulted in lung tumors in rats [115]. SWCNTs containing residual catalytic metals produced greater pulmonary toxicity, including epithelioid granulomas and some interstitial inflammation, than ultrafine carbon black or quartz. These effects extended into the alveolar septa [116]. A review of eleven studies of carbon nanotube introduction to the lungs of mice, rats, and guinea pigs revealed most found granuloma, inflammation, and fibrosis [117]. MWCNTs produced greater acute lung and systemic effects and were twice as likely to activate the immune system as SWCNTs, suggesting the former have greater toxic potential [118]. Further adding to the concern of ENM-induced adverse health effects are reports that inhaled CNTs potentiate airway fibrosis in a murine model of asthma [119], and that exposure of a cell line derived from normal human bronchial epithelial (BEAS-2B) cells to SWCNTs and graphite nanofibers produced genotoxicity and decreased cell viability [120]. However, a point of 
contention is that the lung response to intratracheal and inhaled MWCNTs differed among studies. This may have been due to different sizes and distributions of MWCNT agglomerations. These differences create uncertainties regarding the utility of some routes of pulmonary ENM exposure used in laboratory studies to predict potential toxicity in humans [121].

Studies exposing lung-derived cells in culture to ENMs have demonstrated similar effects. Carbon-based ENMs produced pro-inflammatory, oxidative-stress, and genotoxic effects $[122,123]$.

Several groups have studied the effects of CNT introduction into the peritoneal cavity. As there is CNT translocation from the lung to other sites (see II, D. Clearance of ENMs, their translocation to distal sites, and persistence), and the internal surfaces of the peritoneal and pleural cavities are lined with a mesothelial cell layer, responses in the peritoneal cavity appear to be relevant to the pleural cavity. Single ip injection of high-aspect-ratio MWCNTs $(\sim 100 \mathrm{~nm}$ diameter and $2000 \mathrm{~nm}$ long) produced inflammation, granulomatous lesions on the surface of the diaphragm, and mesothelioma that were qualitatively and quantitatively similar to those caused by crocidolite asbestos, also a highaspect-ratio fiber [124]. These effects correlated positively with the MWCNT aspect ratio [125,126].

Toxicity has also been seen from pulmonary introduction of metal and metal oxide ENMs. Ten and $20 \mathrm{~nm}$ anatase titania induced in BEAS-2B cells oxidative DNA damage, lipid peroxidation, increased $\mathrm{H}_{2} \mathrm{O}_{2}$ and nitric oxide production, decreased cell growth, and increased micronuclei formation (indicating genetic toxicity) [52]. Exposure of BEAS-2B cells to 15- to 45-nm ceria or 21$\mathrm{nm}$ titania resulted in an increase of ROS, increased expression of inflammation-related genes, induction of oxidative stress-related genes, induction of the apoptotic process, decreased glutathione, and cell death $[127,128]$. Twenty-nm ceria increased ROS generation, lipid peroxidation, and cell membrane leakage, and decreased glutathione $\alpha$-tocopherol (vitamin $\mathrm{E}$ ) and cell viability in a human bronchoalveolar carcinoma-derived cell line (A549) [129]. Various metal oxides differentially inhibited cell proliferation and viability, increased oxidative stress, and altered membrane permeability of human lung epithelial cells [130].

\section{ENM exposure effects seen in the brain}

Murine microglial cells were exposed to a commercial 70\%:30\% anatase:rutile titania (primary crystalline size $30 \mathrm{~nm} ; 800$ to $2400 \mathrm{~nm}$ agglomerations in test medium). They displayed extracellular release of $\mathrm{H}_{2} \mathrm{O}_{2}$ and the superoxide radical and hyper-polarization of mitochondrial membrane potential [131]. Intravenous ceria administration to rats altered brain oxidative stress indicators and anti-oxidant enzymes [23,132]. These results demonstrate the ability of metal oxide ENMs to produce neurotoxicity.

\section{ENM exposure effects seen in the skin}

Potential toxicity from dermal exposure was demonstrated with silver ENMs, that decreased human epidermal keratinocyte viability [133]. These results demonstrate the ability of metal oxide ENMs to also produce dermatotoxicity.

\section{Summary of the effects of ENM exposure on target} organs and those distal to the site of uptake

Common findings of many studies are induction of inflammatory processes and oxidative stress. However, correspondence between responses of cells in culture and in vivo models is often low [24,43]. In light of the pressure to minimize whole animal (e.g., rodent) research, further development of cell-based or in vitro models of the whole organism is expected. Additionally, there has been considerable use of alternative model organisms e.g., C. elegans, which has a genome with considerable homology with vertebrate genomes and is often used in ecotoxicological studies, and zebrafish which are often used in developmental biology and genetic studies [134-136].

\section{Dose-response assessment}

Exposure in experimental studies is typically expressed as dose, usually on a mass/subject body weight basis, or as concentration. Dose or concentration may not be the best metric to predict ENM effects [42,53,137]. Neutrophil influx following instillation of dusts of various nanosized particles to rats suggested it may be more relevant to describe the dose in terms of surface area than mass [138]. The pro-inflammatory effects of in vitro and in vivo nanoscale titania and carbon black best correlated when dose was normalized to surface area [122]. Secretion of inflammatory proteins and induction of toxicity in macrophages correlated best with the surface area of silica ENM [139]. Analysis of in vitro reactive oxygen species generation in response to different sized titania ENMs could be described by a single Sshaped concentration-response curve when the results were normalized to total surface area, further suggesting this may be a better dose metric than concentration [53]. Similarly, using surface area as the metric, good correlations were seen between in vivo (PMN number after intratracheal ENM instillation) and in vitro cellfree assays [42].

Nonetheless, most studies of ENMs have expressed exposure based on dose or concentration. The relatively small amount of literature has generally shown dose- or concentration-response relationships, as is usually the case for toxicity endpoints. Ceria ENM uptake into human lung fibroblasts was concentration-dependent for several sizes, consistent with diffusion-mediated uptake 
[58]. Positive, dose-dependent correlations were seen in blood, brain, liver, and spleen following iv ceria infusion in rats, measured by elemental analysis as cerium [23], as well as brain titanium after ip titania injection [140], and lung cobalt after inhalation of cobalt-containing MWCNTs [141]. Concentration-dependent inhibition of RAW 264.7 (murine) macrophage cell proliferation was seen following in vitro SWCNT exposure, as was lipopolysaccharide-induced COX-2 expression, up to $20 \mu \mathrm{g} / \mathrm{ml}$ [142]. Intratracheal instillation of MWCNTs (average length $\sim 6 \mu \mathrm{m}$ ) or ground MWCNTs (average length $\sim 0.7 \mu \mathrm{m}$ ) produced dose-dependent increases in LDH activity and total protein, but no dose-dependent effect on the number of neutrophils or eosinophils, or TNF- $\alpha$, in rat lung bronchoalveolar lavage fluid [143]. Activated Kupffer cell count increased with iv ceria dose; the increase in hippocampal 4-hydroxy-2-trans-nonenal and decrease in cerebellar protein carbonyls (indicators of oxidative stress) were dose-dependent up to a maximum that did not increase further at the highest dose [23].

Some studies demonstrating adverse effects of CNT introduction to the lung have been criticized for using doses or concentrations that far exceeded anticipated human exposure [144]. Most studies assessing potential adverse effects of ENMs have utilized a single exposure. Both of these features make extrapolation of results to prolonged or episodic (periodic) human exposure difficult. However, the study of acute high doses/concentrations to probe potential effects is a standard approach in toxicology and experimental pathology for initially surveying adverse effects (i.e., hazard identification). When adverse effects are seen following some reasonable (e.g., sublethal) dose, subsequent studies must define exposures that do, and do not, result in adverse effects.

\section{The clearance of ENMs, their translocation to distal sites, and persistence}

As with the above studies that inform about uptake, the clearance and translocation of ENMs from the initial site of exposure to distal sites is best understood from whole-animal studies.

The solutes of dissolved particles in the lung can transfer to blood and lymphatic circulation. Some ENMs in the airway wall that slowly dissolve or are insoluble will be cleared within a few days from the lung by cough or the mucociliary escalator. Slowly dissolving and insoluble ENMs that reach the alveoli may be taken up by macrophages. Macrophage-mediated phagocytosis is the main mechanism for clearing foreign material from the deep lungs (alveoli) and from other organs. Macrophages are $\sim 20 \mu \mathrm{m}$ in diameter and able to phagocytose materials up to $15 \mu \mathrm{m}$ in length. They engulf the particle in a vacuole (phagosome) containing enzymes and oxidizing moieties that catabolize it.
Particles resistant to catabolism may remain inside the macrophage. After the death of the macrophage the material may be engulfed by another cell. Therefore, it may take a long time for insoluble material to be cleared from the body. The elimination half-live of insoluble inert particles from the lung can be years [145]. This raises the question of the ultimate fate of "poorly digestible" ENMs that are engulfed by macrophages in the lung, liver (Kupffer cells), brain (microglia), and other organs.

Some ENMs, e.g., those that have a high aspect ratio, are not effectively cleared by macrophages. Alveolar macrophages that cannot digest high-aspect-ratio CNTs (termed "frustrated phagocytosis") can produce a prolonged release of inflammatory mediators, cytokines, chemokines, and ROS [146]. This can result in sustained inflammation and eventually fibrotic changes. Studies have demonstrated MWCNT-induced pulmonary inflammation and fibrosis, similar to that produced by chrysotile asbestos and to a greater extent than that produced by ultrafine carbon black or SWCNTs [117]. Greater toxicity from a high-aspect-ratio metal oxide (titania) ENM has also been shown in cells in culture and in vivo [147]. Studies such as these have raised questions (and concern) about the long-term adverse effects of ENM exposure.

Translocation of ENMs from the lung has been shown. After MWCNT inhalation or aspiration they were observed in subpleural tissue, the site of mesotheliomas, where they caused fibrosis [148,149]. Once ENMs enter the circulatory system across the $0.5-\mu \mathrm{m}$ thick membrane separating the alveoli from blood, the sites of reticuloendothelial system function (including the lymph nodes, spleen, Kupffer cells, and microglia) clear most ENMs. Thirty to $40 \mathrm{~nm}$ insoluble ${ }^{13} \mathrm{C}$ particles translocated, primarily to the liver, following inhalation exposure [150]. Similarly 15 and $80 \mathrm{~nm}{ }^{192}$ iridium particles translocated from lung to liver, spleen, heart, and brain. The extent of translocation was $<0.2 \%$, and greater with the smaller ENMs [151].

ENMs have also been shown to translocate following injection. Indirect evidence was shown of fullerene distribution into, and adverse effects in, the fetus $18 \mathrm{~h}$ after its injection into the peritoneal cavity of pregnant mice on day 10 of gestation [152]. Following subcutaneous injection of commercial 25 to $70 \mathrm{~nm}$ titania particles into pregnant mice $3,7,10$, and 14 days post coitum, aggregates of 100 to $200 \mathrm{~nm}$ titania were seen in the testes of offspring at 4 days and 6 weeks post-partum and in brain at 6 weeks post-partum. Abnormal testicular morphology and evidence of apoptosis in the brain indicated fetal titania exposure had adverse effects on development. The authors attribute these effects to ENM translocation across the placenta [153]. ENM 
excretion into milk and oral absorption post-partum might contribute to ENM presence in the offspring, but we are unaware of any studies assessing ENM translocation into milk. Non-protein bound substances generally enter milk by diffusion, and reach an equilibrium between milk and blood based on their $\mathrm{pKa}$ and the $\mathrm{pH}$ difference between blood and milk, described by the Henderson-Hasselbalch equation. Given the size of most ENMs, it is unlikely they would diffuse across the mammary epithelium. Within 40 weeks after a single intrascrotal injection of MWCNTs most rats died or were moribund with intraperitoneal disseminated mesothelioma, which were invasive to adjacent tissue, including the pleura. Fibrous MWCNT particles were seen in the liver and mesenteric lymph nodes, suggesting peritoneal effects might have been due to MWCNT translocation [154].

The distribution of carbon-, metal- and metal oxidebased ENMs after translocation from the lung, skin or intestine is similar to that seen after their iv administration. They generally appear as agglomerates in the liver and spleen [23,93,132,151,155-158]. The ENMs are usually in the cytoplasm, with little indication that they enter the nucleus [132,134,158-160].

Due to their small size ENMs may gain access to regions of the body that are normally protected from xenobiotics (sanctuaries), such as the brain. This feature has suggested their potential application for drug delivery to the brain, which is being extensively pursued [161-164], but at the same time it raises concern about central nervous system distribution of ENMs when exposure is not intended. Studies have generally found $<<1 \%$ of the administered dose of ceria and iridium ENMs translocate to the brain after inhalation exposure or iv injection $[23,132,151]$. Anionic polymer ENMs entered the brain more readily than neutral or cationic ones. Both anionic and cationic ENMs altered bloodbrain barrier integrity [165].

The persistence of ENMs may be a major factor contributing to their effects. Many ENMs are designed to be mechanically strong and resist degradation [22]. Referring to nanoscale fiber-like structures, it has been stated: "The slower [they] are cleared (high bio-persistence) the higher is the probability of an adverse response" [166]. The analogy of high-aspect-ratio ENMs to asbestos is one of the contributors to this concern. The prolonged physical presence of ENMs, that are not metabolized or cleared by macrophages or other defense mechanisms, appears to elicit ongoing cell responses. The majority of CNTs are assumed to be biopersistent. For example, two months after the intratracheal instillation of $0.5,2$ or $5 \mathrm{mg}$ of $\sim 0.7 \mu \mathrm{m}$ and $\sim 6 \mu \mathrm{m}$ MWCNTs, 40 and $80 \%$ of the lowest dose remained in the lungs of rats, suggesting adequate persistence to cause adverse effects that are summarized in II, B, $\mathbf{1}$ ENM exposure effects in the lung [143]. Following oral administration, 50-nm non-ionic polystyrene ENMs were seen in mesenteric lymphatic tissues, liver, and spleen 10 days later [167]. Following iv administration, carboxylated-MWCNTs were cleared from circulation and translocated to lung and liver; by day 28 they were cleared from the liver, but not from the lung [168]. No significant decrease of the amount (mass) of cerium was seen in the liver or spleen of rats up to 30 days after iv administration of 5 or $30 \mathrm{~nm}$ ceria. Hepatic granuloma and giant cells containing agglomerates in the cytoplasm of the red pulp and thickened arterioles in white pulp were seen in the spleen (unpublished data, R. Yokel) $[159,169]$.

In summary, the persistence of ENMs in tissue raises justifiable concerns about their potential to cause longterm or delayed toxicity.

\section{E. The physico-chemical properties of ENMs that impact their hazard - The role of surface coating in ENM effects} Many surface coatings have been investigated in order to develop ENMs as carriers for drug delivery. Surface modifications can prolong ENM circulation in blood, enhance uptake at a target site, affect translocation, and alter excretion. When ENMs enter a biological milieu they rapidly become surface coated with substances such as fulvic and humic acids and proteins, all of which can alter their effects $[142,170,171]$. When 3.5 , 20, and $40 \mathrm{~nm}$ gold and DeGussa P-25 titania ENMs were incubated with human plasma, proteins appeared to form a monolayer on the ENMs. The abundance of plasma proteins on gold approximated their abundance in plasma, whereas some proteins were highly enriched on titania [172]. Metal oxide and carbon-based ENMs rapidly adsorb proteins [66], resulting in changes in their zeta potential (electrical potential at the ENM surface) and toxicity $[142,171]$. For circulating ENMs, the surface coating is extremely important, because this is what contacts cells [173].

Although it is understood that ENMs will be surface coated with proteins, lipids or other materials, which may or may not persist on the ENM surface when they enter cells, little is known about the surface associated molecules on ENMs within cells. It is likely, however, that surface coatings profoundly influence ENM effects within cells. Although surface functional groups are known to modify ENM physico-chemical and biological effects, there is little information on the influence of functional groups on health effects. This further complicates the prediction of ENM toxicity in humans from in vitro, and perhaps in vivo, studies. 


\section{F. The effects of ENMs at distal sites}

Reported systemic effects of pulmonary-originating CNTs include acute mitochondrial DNA damage, atherosclerosis, distressed aortic mitochondrial homeostasis, accelerated atherogenesis, increased serum inflammatory proteins, blood coagulation, hepatotoxicity, eosinophil activation (suggesting an allergic response), release of IL-6 (the main inducer of the acute phase inflammatory response), and an increase of plasminogen activator inhibitor-1 (a pro-coagulant acute phase protein) [118]. Elevation of the serum analyte ALT was reported up to 3 months after intratracheal MWCNT instillation, suggesting ENM-induced hepatotoxicity [174]. The translocation of ENMs and their release of cytokines and other factors could potentially affect all organ systems, including the brain. For example, daily ip injection of titania for 14 days resulted in a dose-dependent increase of titanium and oxidative stress and a decrease of anti-oxidative enzymes in the brain of rats [140].

\section{Hazard Assessment from Fire and Explosion of ENMs}

Some ENMs have very high reactivity for catalytic reactions, thus raising the possibility of fire and/or explosion. As particle size decreases and surface area increases, the ease of ignition and the likelihood of a dust explosion increase. The latter may create a second hazard due to increased ENM release. There are no reports that ENMs have been used intentionally, e.g. by terrorists, or unintentionally to cause fires, explosions, or an airborne obscurant effect.

\section{Exposure Assessment}

Another key element of the Risk Assessment/Risk Management framework is exposure assessment, which includes the most likely routes of ENM exposure. Not much is known about the extent of occupational exposure to ENMs. There are 20 published studies [51]. "In the absence of solid exposure data, no solid risk evaluation can be conducted" [175]. There is obvious value in conducting exposure assessments in the workplace to identify the routes, extent, and frequency of ENM exposure. In assessing worker exposure, the traditional industrial hygiene sampling method of collecting samples in the breathing zone of the worker (personal sampling) is preferred over area sampling. Only a few of the studies cited [51] conducted breathing zone measurements. On the other hand, area samples (e.g., size-fractionated aerosol samples) and real-time (direct-reading) exposure measurements are useful for evaluating engineering controls, and their efficacy, and work practices.

When monitoring potential workplace exposure to ENMs it is critical that background nanoscale particle measurements be conducted before their production, processing, or handling in order to obtain baseline data. Nanosize particles frequently come from non-ENM sources, such as ultrafines from internal combustion engines and welding $[176,177]$.

An early study of SWCNT release during its handling in the workplace showed very low airborne concentrations of agglomerated material [178]. The rapid agglomeration of ENMs in air has been repeatedly shown $[55,178,179]$. Airborne ENMs associate with other airborne materials when present, or self-associate in their absence. Once formed there was little decrease in the resultant airborne agglomerations for up to $4 \mathrm{~h}$ [55]. An on-site monitoring study of carbon nanofibers (CNFs) in a university-based research laboratory showed an increase of $>500-\mathrm{nm}$ particles in air during weighing and mixing (total carbon levels in inhalable dust samples of 64 and $93 \mu \mathrm{g} / \mathrm{m}^{3}$, respectively). Handling the bulk partially-dry product on the lab bench generated $221 \mu \mathrm{g} / \mathrm{m}^{3}$, and wet-saw cutting (which sprays water on the object being cut to lessen dusts) of a CNF composite released $>400-\mathrm{nm}$ particles $\left(1094 \mu \mathrm{g} / \mathrm{m}^{3}\right)$. Office background was 15 to $19 \mu \mathrm{g} / \mathrm{m}^{3}$. Surface samples had up to 30-fold more total carbon than the office floor [180]. Another study showed that wet cutting of a hybrid $\mathrm{CNT}$ in an epoxy resin or in a woven alumina fiber cloth using a cutting wheel with water to flush dust particles produced no significant increase of airborne 5- to 1000$\mathrm{nm}$ particles in the operator breathing zone, whereas dry machining did [181]. Production of a nanocomposite containing alumina in a polymer by a twin-screw extrusion process caused release of 5- to 20-nm and 50- to 200-nm alumina in the worker's breathing zone [182]. Covering the top of the feeding throat and the open mouth of the particle feeder, thorough cleaning by washing the floor, and water-based removal of residual dust on all equipment significantly decreased airborne particles [182,183]. These results suggest that some engineering controls may be appropriate to safely remove some airborne ENMs, including maintaining the room at negative pressure relative to the outside, avoiding the handling of dry ENMs, adequate ventilation, and containment of the ENM material during its use.

NIOSH researchers developed a Nanoparticle Emission Assessment Technique (NEAT) for use in the workplace [56]. They used the technique to determine particle number concentrations using two hand-held, direct-reading, particle number concentration-measuring instruments, a condensation and an optical particle counter, to survey 12 sites working with ENMs. This was complemented by collection of particles on filters and transmission electron microscopic visualization. The results demonstrated the utility of NEAT and, in some cases, the source of ENM release and efficacy of engineering controls [179]. Engineering controls are discussed in more detail below. 
There are numerous reports of adverse lung effects, and some reports of human deaths, from nanosized polymer fumes[26]. Two deaths were reported among seven 18- to 47-year-old female workers exposed to polyacrylate nanoparticles for 5 to 13 months. Cotton gauze masks were the only PPE used, and were used only occasionally. The workplace had one door, no windows, and no exhaust ventilation for the prior 5 months [184]. Workers presented with dyspnea on exertion, pericardial and pleural effusions, and rash with intense itching. Spirometry showed that all suffered from small airway injury and restrictive ventilatory function; three had severe lung damage. Non-specific pulmonary inflammation, fibrosis, and foreign-body granulomas of the pleura were seen. Fibrous-coated nanoparticles $(\sim 30$ $\mathrm{nm}$ ) were observed in the chest fluid and lodged in the cytoplasm, nuclei, and other cytoplasmic organelles of pulmonary epithelial and mesothelial cells. Two workers died of respiratory failure. Although presented as the first report of clinical toxicity in humans associated with long-term ENM exposure, many experts have expressed uncertainty that ENMs contributed to these outcomes $[22,185,186]$. Given the poor environmental conditions of the workplace and lack of effective PPE use, these outcomes could probably have been prevented.

\section{Risk Characterization}

The giant insurance firm Lloyd's of London conducted a risk assessment and concluded "Our exposure to nanotechnology must therefore be considered and examined very carefully" [http://www.nanolawreport.com/2007/12/ articles/review-lloyds-new-nano-insurance-report/]. Japan's Ministry of Health, Labour and Welfare funded studies starting in 2005 to establish health risk assessment methodology of manufactured nanomaterials. It was recently concluded that studies of metals and SWCNTs from Japan are not yet sufficient to evaluate ENM risk [187]. However, a new study incorporated a physiologically-based lung model and data of particle sizes of airborne titania ENM during manufacturing to estimate anatase and rutile titania ENM burdens and adverse effects in lung cells. The authors concluded that workers exposed to relatively high airborne 10- to 30$\mathrm{nm}$ anatase titania are unlikely to have substantial risk for lung inflammatory responses, but are at risk for cytotoxicity [188]. Risk characterization and assessment and gap analysis case studies were conducted with fullerenes, CNTs, silver as a example of a metal, and titania as an example of a metal oxide ENM [189]. Numerous additional data gaps were identified for each.

\section{Risk Management}

There are no existing regulations or standards for ENMs within the three jurisdictions that have the largest nanotechnology funding, the U.S., EU and Japan [190]. In the U.S. OSHA would set standards for occupational exposure to ENMs. Three types of standards are relevant for ENMs under the Occupational Safety and Health Act [191]. 1) Substance-specific standards, for which there are none for ENMs. 2) General respiratory protection standards, under which inhalable ENMs would be considered particulates not otherwise regulated, e.g. "nuisance dust", with a $5 \mathrm{mg} / \mathrm{m}^{3}$ timeweighted average air exposure limit, determined by breathing-zone air samples. The respiratory protection standard requires employers provide workers with $\mathrm{NIOSH}$-certified respirators or other PPE when engineering controls are not adequate to protect health. 3) The hazard communication standard states producers and importers of chemicals must develop Material Safety Data Sheets [191]. The U.S. EPA, using the legislative authority of the Toxic Substances Control Act has taken steps to limit the use and exposure to ENMs, including CNTs. EPA has required the use of PPE and limitiation on ENM use and environmental exposures [22]. NIOSH prepared a draft Current Intelligence Bulletin: "Occupational Exposure to Carbon Nanotubes and Nanofibers" (http://www.cdc.gov/niosh/docket/review/ docket161A/pdfs/carbonNanotubeCIB_PublicReviewOfDraft.pdf). NIOSH recommends an 8-hour timeweighted average exposure limit of $7 \mu \mathrm{g}$ carbon nanotubes and nanofibers $/ \mathrm{m}^{3}$ air, and that employers minimize exposure to these materials. Suggested implementation includes many of the primary prevention measures discussed in this review and an occupational health surveillance program of exposure and medical monitoring. Given the $7 \mu \mathrm{g} / \mathrm{m}^{3}$ level is below total airborne carbon in non-CNT-production settings (offices) [180], the ubiquitous presence of CNTs which is probably due to hydrocarbon combustion [192], and the necessity to differentiate CNTs from other carbon sources to estimate airborne nanotube and nanofiber concentration, assuring their airborne level of $<7 \mu \mathrm{g} / \mathrm{m}^{3}$ may be difficult.

The goal in managing the potential risks from ENMs is to minimize exposure. In the absence of specific information on ENMs, the extensive scientific literature on airborne, respirable aerosols and fibers has been used to develop interim guidance for working safely with ENMs [193] [http://ehs.mit.edu/site/content/nanomaterialstoxicity] [http://www.astm.org/Standards/E2535.htm]. The general approach to minimizing exposure is shown in Figure 4, with the preferred followed by less desireable controls shown by the downward pointing arrow. Occupational health surveillance, which includes hazard and medical surveillance, is the process whereby information from any of these activities is collected and used to support or modify what is done at a higher step in 


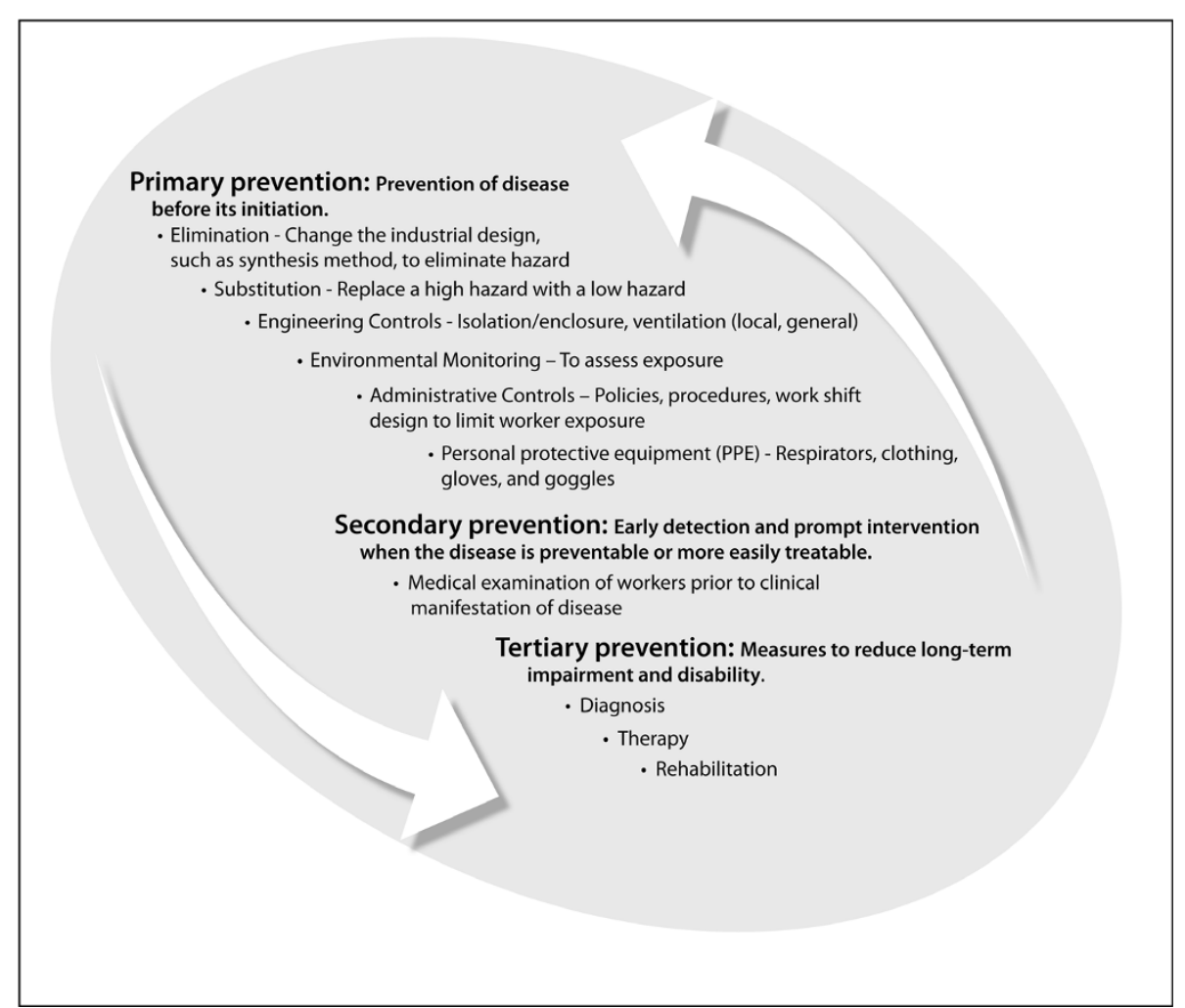

Figure 4 Elements of occupational health protection. The continuum of prevention and the heirarchy of exposure control (left arrow) and occupational health surveillance (right arrow). Adapted from [222] and [194].

the hierachy, as shown by the upward pointing arrow [194]. Those steps in the hierachy that have been investigated for ENMs are further discussed below.

\section{A. Engineering controls}

ENM exposure can be reduced through the use of engineering controls, such as process changes, material containment, and enclosures operating at negative pressure compared to the worker's breathing zone; worker isolation; separated rooms; the use of robots; and local exhaust ventilation (LEV). Given the lack of occupational exposure standards to provide guidance, the most prudent approach is to minimize exposure. A survey found that engineering controls in Switzerland were more commonly used in the production of powder than liquid ENMs. For the former, the use of PPE (masks, gloves, safety glasses, or full protective suits) were the norm, although used by only $\sim 16,19,19$, and $8 \%$ of the workers, respectively [195]. This low use of PPE is thought to reflect the early stage of development of the ENM industry. It is anticipated that as this industry matures and knowledge is gained, control will more commonly include superior methods in the hierarchy of exposure control [196]. An international survey of ENM industry managers conducted in 2009-2010 by the
University of California Center for Environmental Implications of Nanotechnology that focused on industry controls of ENM exposure, use of PPE, environmental risks, and perceptions revealed that $46 \%$ of the companies had a nano-specific environmental health and safety program, compared to 58\% in a 2006 survey [197]. Some companies (a minority) were using inappropriate occupational environmental clean-up methods, such as sweeping and compressed air [198]. These results suggest more widespread adoption of nano-specific environmental health and safety programs and the use of PPE in the absence of superior controls are appropriate.

\section{Process containment}

Process/source enclosure (i.e., isolating the ENM from the worker) can be aided by glove boxes, chemical fume hoods, biological safety cabinets (BSC), or an externallyvented LEV system. However, one should also consider that these methods can release ENMs into the environment, potentially creating environmental pollution and loss of costly material.

ENM handling is often conducted in fume hoods. Field sampling conducted to determine fume hood, work zone, and background concentrations of $\mathrm{PM}_{2.5}(<$ $2.5 \mu \mathrm{m})$ particles during production of fullerenes and other carbon-containing ENMs showed handling 
produced aerosolization of 5 to $100 \mathrm{~nm}$ particles, which were contained by the fume hood [199]. Monitoring aerosolized particles during chemical vapor deposition (CVD) SWCNT synthesis and aerosol-assisted CVD MWCNT synthesis in a fume hood showed significant release at the source, but not outside of the hood, suggesting fume hood use did not create fugitive airborne emissions and was necessary to protect workers [144]. These authors also determined the release of dry powder alumina (27 to $56 \mathrm{~nm}$ primary particle size, $200 \mathrm{~nm}$ agglomerates) and $60 \mathrm{~nm}$ silver ENM into the researcher's breathing zone and laboratory environment when poured or transferred in 3 fume hoods; 1 ) a conventional hood that has a constant air flow with velocity inversely related to sash height, 2) a by-pass hood which attempts to maintain a constant velocity by use of a bypass grill above the hood which becomes uncovered, allowing more air flow through it rather than the hood face as the sash is lowered, and 3) a constant velocity (variable air volume) hood that uses a motor to vary fan speed as the sash is moved. The results showed significant release of ENMs into the researcher's breathing zone and laboratory environment and identified the variables affecting release. These included hood face velocities $<80 \mathrm{ft} / \mathrm{min}(<0.4 \mathrm{~m} / \mathrm{s}$ ) (due to room air currents and operator movements) and $>120 \mathrm{ft} / \mathrm{min}(>0.6$ $\mathrm{m} / \mathrm{s}$ ) (due to turbulence within the hood). The constant velocity hood performed better than the by-pass hood, which in turn performed better than the conventional hood [200]. Tests were also conducted with alumina nanoparticles (primary particle size 27 to $56 \mathrm{~nm}$; present as dry bulk material $\sim 200 \mathrm{~nm}$ ) to compare particles in the breathing zone during transfer and pouring in constant flow, constant velocity and air-curtain hoods. The newly developed air-curtain hood is evidently not commercially available. The results showed much lower levels with the air curtain hood [201]. Sash height, which affected hood face velocity, affected ENM release. Rapid removal of the worker's arm from a BSC also withdrew ENMs, releasing them outside the cabinet. Worker motion and body size affected ENM release from a traditional, but not the air-curtain, hood. The authors found that ENM handling in traditional fume hoods with a face velocity of 0.4 to $0.5 \mathrm{~m} / \mathrm{s}(\sim 80$ to 100 $\mathrm{ft} / \mathrm{min}$ ) and careful motions minimized fugitive ENM emission. In 2008 the Center for High Rate Manufacturing recommended locating equipment at least 6 inches $(15 \mathrm{~cm})$ behind the sash, minimizing hood clutter, and avoiding rapid or violent motions while working in the hood [202]. In a study conducted in an industrial setting, use of an exhaust hood during procedures that are more likely to release ENMs (their production, handling, measurement, and reactor cleanout) resulted in no significant increase of ENMs in the workplace [203]. These studies show that significant reduction of worker exposure to ENMs can be achieved using available fume hoods and consideration of worker activities within these hoods.

Labconco Corporation has marketed a modified Class I BSC for handling nanoparticles [http://www.labconco. com/_scripts/editc20.asp?CatID=82]. It has an all stainless steel interior for ease of cleaning, perforated rear baffle to reduce turbulence, and a replaceable HEPA filter. It is available with a built-in ionizer to attract particles to the interior surface of the hood, and an external exhaust for volatiles.

\section{Local exhaust ventilation (LEV)}

Air-displacement ventilation in an industrial setting was accomplished by introduction of supply air that entered at low velocity at the floor level and was cooler than room air. As the air rose it became warmer and was exhausted close to the ceiling. This provided efficient clearing of ENMs from the breathing zone [204].

A well-designed exhaust ventilation system with a HEPA filter should effectively capture airborne nanoparticles. A "down flow" booth, "elephant trunk", or fume hood may not provide sufficient protection because they may cause turbulence, spinning the ENM out of the airflow [201].

The effectiveness of engineering controls in ENM production and research facilities has been demonstrated in a few cases. Prior to use of engineering-control measures, total airborne mass concentrations of MWCNTs, measured by area sampling, were 0.21 to $0.43 \mathrm{mg} / \mathrm{m}^{3}$ in a laboratory research facility where the powders were blended to formulate composites. After enclosing and ventilating the blending equipment and re-locating another piece of equipment that produced considerable vibration, the concentration decreased to below the limit of detection [205]. In another study, the effectiveness of LEV was assessed during clean-out of slag and waste, which used brushes and scrapers, of reactors that produced 15 to $50 \mathrm{~nm}$ diameter ENMs. A portable LEV unit was used that had been shown to reduce welding fume exposure [206]. The reduction in release of 300to $10,000-\mathrm{nm} \mathrm{Ag}, \mathrm{Co}$, and $\mathrm{Mn}$ particles during cleanout of reactors used to make nanoscale metal catalytic materials was 75 , 94, and 96\%, respectively [207].

During the manual sanding of epoxy test samples reinforced with MWCNTs, an order of magnitude more particles, which were predominantly $>300 \mathrm{~nm}$, was observed in a worker's breathing zone when the work was conducted in a custom fume hood rather than on a work table with no LEV. The poor performance of the custom fume hood may have been due to the lack of a front sash and rear baffles, and to low face velocity ( 0.39 $\mathrm{m} / \mathrm{sec}$ ). Respirable particles were an order of magnitude lower when the work was conducted in a BSC than on a 
work table [208]. These results illustrate the importance of good exhaust hood design as well as the worker protection provided by a BSC.

\section{B. Administrative controls}

When engineering controls are not feasible for reducing exposure, administrative controls should be implemented. These are policies and procedures aimed at limiting worker exposure to a hazard [209]. These could include a nanoscale material hygiene plan; preparation, training in, and monitoring use of standard operating procedures; reduction of exposure time; modification of work practices; and good workplace and housekeeping practices. For example, one laboratory was thoroughly cleaned after high air concentrations of nanoscale materials were measured in a facility engaged in the commercial compounding of nanocomposites [183]. A large decrease of airborne 30 to $100 \mathrm{~nm}$ particles resulted. Subsequent routine maintenance kept the particles below those originally observed, leading the authors to conclude that this administrative control was beneficial in reducing potential exposure. Biological monitoring and medical examination, a component of secondary prevention (Figure 4), is another administrative control [209]. It is discussed below.

\section{Personal protective equipment}

The last line of defense in the hierarchy of exposure control is the use of PPE, such as respirators, protective clothing, and gloves.

\section{Respirators}

Major types of respiratory protection include dust masks, filtering facepiece respirators, chemical cartridge/ gas mask respirators, and powered air-purifying respirators. Examples can be seen at OSHA's Respiratory Protection Standard site [http://web.utk.edu/ ehss/pdf/rpp. pdf].

NIOSH classifies filter efficiency levels as Type 95, 99, and 100, which are 95, 99, and 99.7\% efficient, respectively. The filter's resistance to oil is designated as N, R, and P; N (not resistant to oil), R (resistant to oil), and P (oil proof). Some industrial oils can remove electrostatic charges from filter media, reducing filter efficiency. Efficiency of $\mathrm{N}$ filters is determined using 300-nm median aerodynamic, charge neutralized, $\mathrm{NaCl}$ particles at a flow rate of $85 \mathrm{l} / \mathrm{min} ; \mathrm{R}$ and $\mathrm{P}$ filters are tested with dioctyl phthalate oil. The European Standards (EN 143 and EN 149) rank filtering facepiece (FFP) respirators as FFP1, FFP2, and FFP3, which are 80, 94, and 99\% efficient, respectively, indicated by CE (for Conformité Européene) on complying products. They are tested with non-neutralized $\mathrm{NaCl}$ at $95 \mathrm{l} / \mathrm{min}$.

Particles $>100 \mathrm{~nm}$ are collected on filter media by two mechanisms: 1) inertial impaction in which air flow deviates around the fiber but large denser-than-air particles do not and impact the fiber due to their inertia, as shown in Figure 5; and 2) interception where the particle trajectory takes it within a particle radius of the fiber, which captures the particle. Airborne nanoparticles behave much like gas particles. Particles $<100 \mathrm{~nm}$
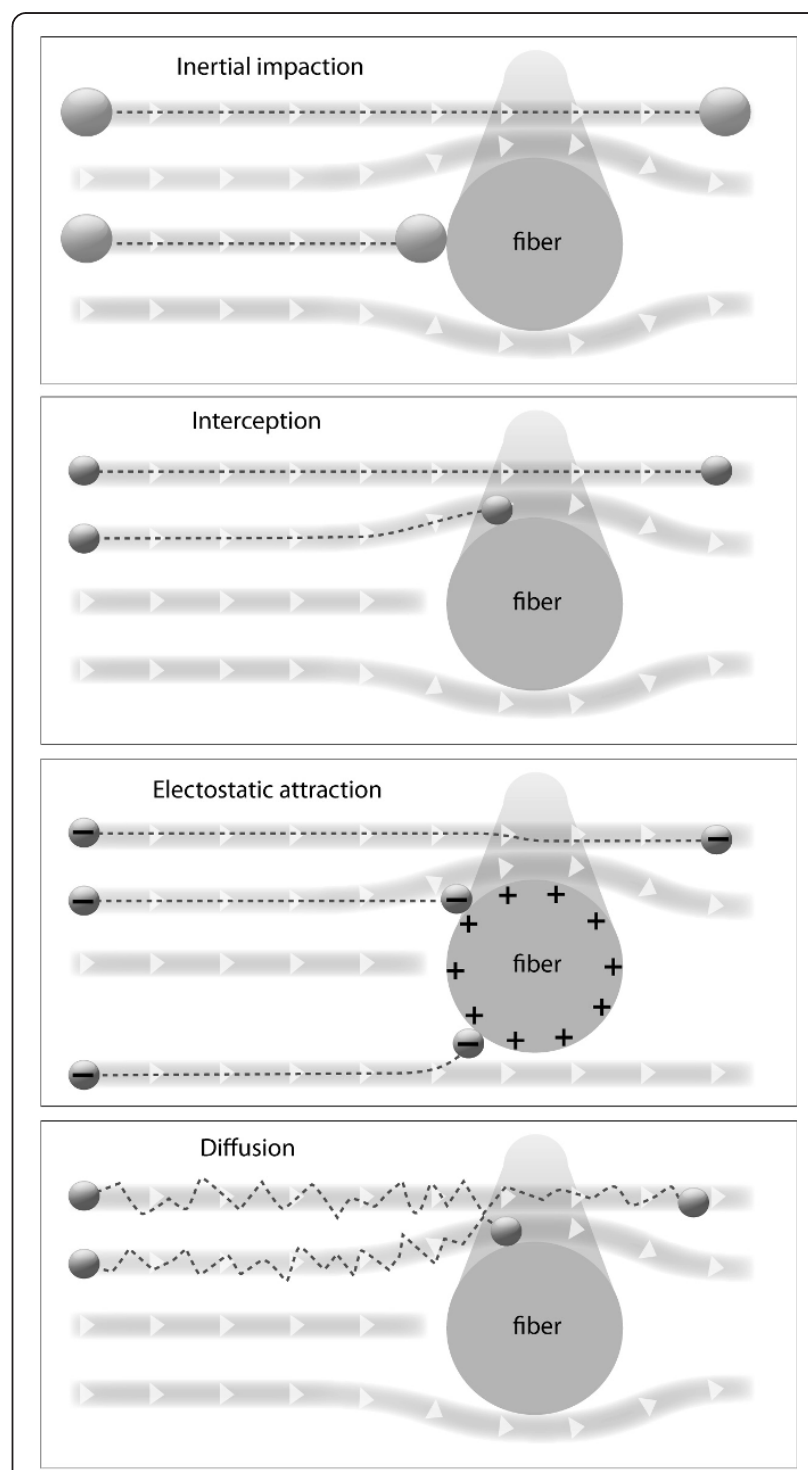

Figure 5 The mechanisms of ENM association with fiber materials. Each panel shows particles carried by airstreams, indicated by the bands with right pointing arrows. Some particles are retained by the fiber. Those that are not continue on the airstream past the fiber. The upper panel shows a large particle that is unable to follow the airstream around the fiber and collides with the fiber due to inertial impaction. The particle trapped by interception comes close enough to the fiber (within the particle radius) that it is captured by the fiber. Electrostatic attraction is discussed in the text VI, C, $\mathbf{1}$. Respirators. Small particles collide with each other, gas molecules, and other suspended matter in the air stream, resulting in Brownian motion and a random zigzagging path of movement, which may cause the particle to hit the fiber, as shown in the diffusion panel. 
are collected by diffusion. Charged particles are trapped by electrostatic attraction, which involves an electrically charged particle and an electrically charged (electret) fiber. Electret filters are constructed from charged fibers. This appears to be a significant mechanism for respirator trapping of ENMs [210]. Neutral particles that pass through a charged fiber can be polarized by the electric field, thereby inducing charge to the particle. In dry conditions, ENM penetration decreases with time. With continued use, however, ENM penetration through an electrostatic filter increases; this was suggested to be due to the humidity of exhalation [211]. Soaking fiber filters in isopropanol removes electrostatic charge. Studies treating filtering facepiece respirators with isopropanol, and then drying them, showed increased penetration of particles $>30 \mathrm{~nm}$ [210], indicating electrostatic charge is a significant mechanism of fiber entrapment of ENMs above this size.

Figure 6 shows results of some studies that assessed the efficacy of different types of dust masks and filtering facepiece respirators to retain ENMs. Most of the studies were conducted with different sizes of $\mathrm{NaCl}$, but a few used silver, graphite or titania. The results show that dust masks purchased at hardware or home improvement stores would not be expected to protect the wearer. The results also show that the NIOSH and CE respirators generally limit penetration of ENMs to concentrations below their ranked efficiency level, which is based on $300 \mathrm{~nm}$ particles, except for the N99 filter, which did not retain more than $99 \%$ of nanoscale $\mathrm{NaCl}$ (Panel D). Most of the results shown were obtained with a flow rate of $85 \mathrm{l} / \mathrm{min}$ (modeling heavy work load). Flow rate affects particle penetration; an example is shown in Panel C where $30 \mathrm{l} / \mathrm{min}$ (modeling low/ moderate intensity work) and $85 \mathrm{l} / \mathrm{min}$ flow rates were compared. Increasing flow rate increased penetration. This was further shown in a comparison of 30,85 , and 150 l/min flow rates with N95 and N99 filtering facepiece respirators [212], which is not shown in Figure 6. This highest flow rate was intended to model an instantaneous peak inspiratory flow during moderate to strenuous work. A similar result of ENM penetration positively correlating with air flow rate is shown in Panel F, where 5.3 and $9.6 \mathrm{~cm} / \mathrm{sec}$ face velocity rates were compared.

The results shown in Figure 6 also indicate ENM penetration is influenced by particle composition. Panel $G$ shows greater penetration of titania than graphite through FFP3 respirators under the same experimental conditions. Panel $\mathrm{H}$ shows greater penetration of 20 to $30 \mathrm{~nm} \mathrm{NaCl}$ than silver ENMs of the same size through P100 filters. These results suggest further work is warranted to understand the influence of the physico-chemical properties of ENMs, particularly size, charge, and shape, on their penetration through filtering facepiece respirators. An issue that significantly impacts filtering facepiece respirator effectiveness is its seal around the face. "The biggest source of leakage is around the respirator seal because of poor fit" (Ronald E. Shaffer quoted in [213]). It has been estimated that $20 \%$ or more leakage occurs in respirators that are not properly fitted [214]. This underscores the importance of a proper fit for face mask respirators.

There is a particle size that maximally penetrates each filter material; the most penetrating particle size (MPPS). The results shown in Figure 6 indicate that the MPPS is $\sim 40$ to $50 \mathrm{~nm}$ for ENMs. This is approximately the same size of spherical ENMs that appear to contribute to their greatest differences in biological systems from solution and bulk forms of the same materials, as discussed in II, A, 2. The physico-chemical properties of ENMs that impact their uptake. This feature raises concern because the size of ENMs that may have the greatest effects in people are those that are best able to penetrate filtering facepiece respirators.

Until results are obtained from clinical-laboratory or work-place studies, traditional respirator selection guidelines should be used. These are based on OSHA Assigned Protection Factor values (the workplace level of respiratory protection that a respirator is expected to provide), the British Standards Institution Guide to implementing an effective respiratory protective device programme (BS 4275), and BS EN 529:2005 (Respiratory protective devices. Recommendations for selection, use, care and maintenance. Guidance document).

\section{Protective clothing}

No guidelines are available on the selection of clothing or other apparel (e.g., gloves) for the prevention of dermal exposure to ENMs. This is due in part to the minimal data available on the efficacy of existing protective clothing, including gloves. Penetration of 10 to $1000 \mathrm{~nm}$ $\mathrm{NaCl}$ through woven and fibrous fabrics showed a MPPS between 100 and $500 \mathrm{~nm}$ and maximum penetration of 50 to $80 \%$ [215]. Comparison of graphite nanoparticle penetration through $650 \mu \mathrm{m}$ thick cotton, 320 $\mu \mathrm{m}$ polypropylene, and $115 \mu \mathrm{m}$ non-woven high-density polyethylene textile (Tyvek ${ }^{\circledR}$ ) showed $\sim 30,12$, and $4 \%$ penetration of the MPPS ( 40 nm), respectively [216]. Tyvek ${ }^{\circledR}$ permitted $\sim 3$ orders of magnitude less penetration of $\sim 10 \mathrm{~nm}$ titania and platinum than cotton or a $160 \mu \mathrm{m}$ woven polyester [217]. A study of ten nonwoven fabrics under conditions simulating workplace ENM exposure showed penetration increased with increasing air velocity and particle size (to $\sim 300$ to $500 \mathrm{~nm}$ ). Pore structure of the various fabrics greatly influenced penetration [218]. Although nonwoven fabrics were much more effective to protect workers from ENM exposure than woven fabrics, they are much less comfortable to 
B
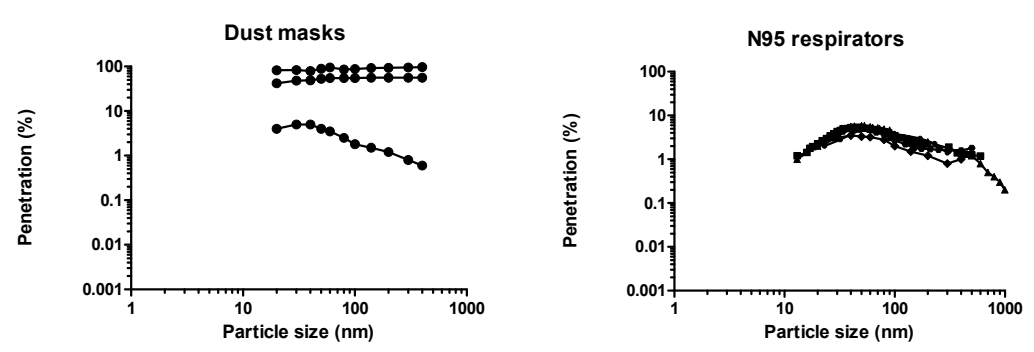

C

D

N95 30 and $85 \mathrm{l} / \mathrm{min}$ flow rates

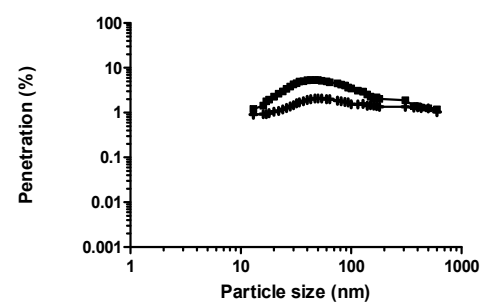

E

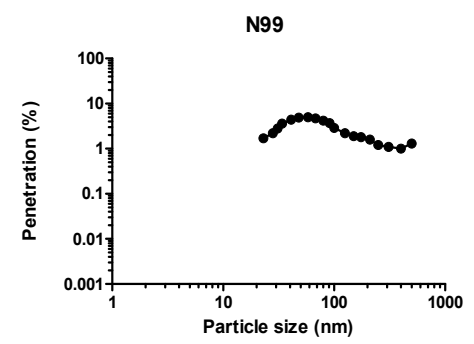

F

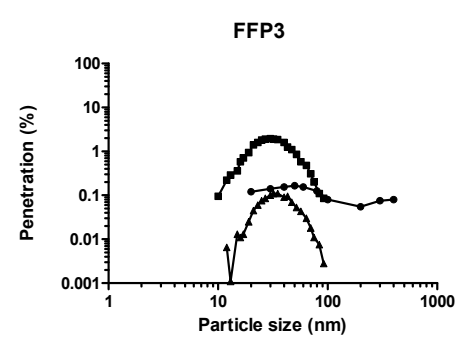

$\mathrm{H}$

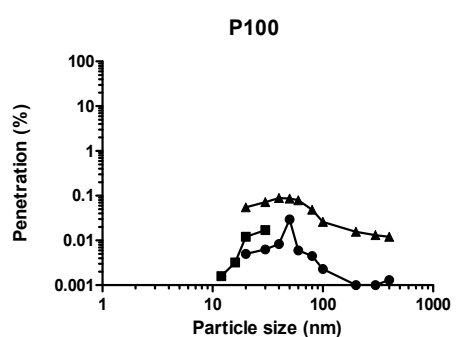

Figure 6 Particle penetration through dust masks and facepiece respirators. Test material was $\mathrm{NaCl}$, flow rate $85 \mathrm{l} / \mathrm{min}$ and values shown are mean, unless noted otherwise. Panel A: Dust masks. Results shown are the mean and most and least efficient of 7 commercially available dust masks, as purchased in home improvement/hardware stores [225]. Panel B. N95 respirators. (Circle) Results from 6 3M Engineered nanoparticles and particulate respirators [http://multimedia.3m.com/mws/mediawebserver?

mwsld=66666UuZjcFSLXTtN8T_NXM2EVuQEcuZgVs6EVs6E666666-]. (Square) Results from $n=2$ [226]. (Triangle) Results from $n=1$ at face velocity of $8.6 \mathrm{~cm} / \mathrm{sec}$ [210]. (Diamond) Results from $n=5$ [227]. (Hexagon) Results from $n=1$ [212]. Panel C. N95 respirators at two flow rates. Results from $n=2$ [226]. Panel D. N99 respirators. Results from $n=2$ [212]. Panel E. FFP2 respirators. Results from $n=2$ [228]. Panel F. FFP3 respirators. (Circle) Results from $n=1$ [228]. (Square) Results from $n=1$, with graphite at a face velocity of $9.6 \mathrm{~cm} / \mathrm{sec}$, flow rate not reported [211]. (Triangle) Results from $n=1$, with graphite at a face velocity of $5.3 \mathrm{~cm} / \mathrm{sec}$, flow rate not reported [211]. Panel G. FFP3 respirators. (Circle) Results from $n=1$, with graphite at face velocity of $5.3 \mathrm{~cm} / \mathrm{sec}$, flow rate not reported [217]. (Square) Results from $n=1$, with titania at face velocity of $5.3 \mathrm{~cm} / \mathrm{sec}$, flow rate not reported [217]. Panel H. P100 respirators. (Square) Results from $\mathrm{n}=2$ with silver particles [229]. (Triangle) Results from $n=2$ with $\mathrm{NaCl}$ [229]. (Circle) Results from $n=2$ with NaCl [228]. 
wear, suggesting improvements in fabric design or selection are needed to address this disincentive to use more effective PPE. The selection of laboratory coat materials can greatly influence the potential penetration of ENMs, which may end up on or penetrating street clothing, resulting in worker absorption or their even greater dispersion into the environment.

\section{Gloves}

An unpublished study reported in 2005 the interaction of alumina and organoclay ENMs with powder-free (natural rubber) latex, powder-free (synthetic latex) nitrile, and cotton gloves [219]. Scanning electron microscopy showed that latex and nitrile gloves exhibited micrometer-sized surface pores/intrinsic voids. Although these surface imperfections were not complete holes, they may serve as pathways for the penetration of nanoparticles under unfavorable conditions, such as stretching and tearing. Stretching the latex and nitrile gloves to $200 \%$ of their original size greatly increased the pores/ intrinsic voids. The surface pores may be important if they collect nanoparticles and the user does not remove the gloves when going to another location, thereby transporting the ENMs. Not surprisingly, there were wider gaps between the fibers in cotton gloves. The authors pointed out that ENMs may be treated with special coatings to enhance their dispersion characteristics, which may alter their permeability through glove materials. This study, however, did not determine the penetration of ENMs through gloves.

Nitrile, latex, and neoprene gloves prevented $\sim 10 \mathrm{~nm}$ titania and platinum ENM penetration [217]. Double gloving has been suggested [219], which should reduce material penetration when there is glove perforation as well as dermal contamination when removing a contaminated outer glove. However, double gloving has not been shown to significantly decrease material penetration [220].

\section{Biological monitoring and medical examination}

Secondary prevention in the continuum of the prevention and heirarchy of exposure control (Figure 4) includes biological monitoring and medical examination, the early detection of asymptomatic disease, and prompt intervention when the disease is preventable or more easily treatable [221]. Occupational health surveillance is the process by which information obtained from any activity in the continuum of prevention and heirarchy of exposure control is collected and used to support or alter what is done at a step higher in the heirarchy, as shown in the right upward pointing arrow in Figure 4 and discussed in [194]. Occupational health surveillance is the ongoing systematic collection, analysis, and dissemination of exposure and health data on groups of workers for the purpose of early detection and injury. It includes hazard surveillence, the periodic identification of potentially hazardous practices or exposures in the workplace, assessing the extent to which they can be linked to workers, the effectiveness of controls, and the reliability of exposure measures. A goal is to help define effective elements of the risk management program for exposed workers. Occupational health surveillance also includes medical surveillance, which examines health status to determine whether an employee is able to perform essential job functions [222]. It is required when there is exposure to a specific workplace hazard (OSHA, 29 CFR 1910.1450). This is different than medical screening or monitoring, a form of medical surveillance designed to detect early signs of work-related illness by administering tests to apparently healthy persons to detect those with early stages of disease or those at risk of disease. NIOSH concluded: "Currently there is insufficient scientific and medical evidence to recommend the specifc medical screening of workers potentially exposed to engineered nanoparticles" [222].

\section{E. Diagnosis, therapy, and rehabilitation}

The third level in the continuum of prevention and heirarchy of exposure control, tertiary prevention, includes diagnosis, therapy, and rehabilitation. Owing to the lack of documented episodes of ENM exposure in humans that have resulted in adverse outcome, there is little experience with treatments of ENM exposure. One example that illustrates clever application of the knowledge of ENM properties was the use of UV light to visualize and treat the accidental dermal exposure of a human to quantum dots suspended in solution [223].

\section{Good work practices}

Based on the current knowledge of ENM exposure risks, some good workplace practices have been suggested. They are shown in Appendix 1.

\section{An example of risk analysis and implementation of actions} to limit ENM exposure

A recent study applied the principles of the Risk Assessment/Risk Management framework to identify and evaluate the potential hazards in a facility manufacturing ENMs [224]. The investigators established a measure of risk for each potential hazard and suggested improvement actions. These were then addressed with administrative controls, environmental monitoring, PPE and good workplace practices.

\section{Some published guidelines for safe handling and use of ENMs}

The following are some published guidelines, not regulations, for safe handling and use of ENMs. The Bundesanstalt für Arbeitsschutz und Arbeitsmedizin (BAUA) provided a "Guidance for handling and use of nanomaterials in the workplace" in 2007 [http://www.baua.de/ en/Topics-from-A-to-Z/Hazardous-Substances/ 
Nanotechnology/pdf/guidance.pdf;jsessionid=E81EECA3E6B5AD1A0D3D2396C4220AF5.2_cid137?__blob=publicationFile\&v=2]. The Environmental Health and Safety office at the University of California provided "Nanotechnology: Guidelines for safe research practices" as their Safety Net \#132 guidelines [http://safetyservices. ucdavis.edu/safetynets/Safetynets-Master\%20List/Safetynets-Master\%20List/safetynet-132-nanotechnologyguidelines-for-safe-research-practices]. Similarly, the Office of Environment, Health \& Safety at the University of California prepared "Nanotechnology: Guidelines for Safe Research Practices" as their publication for the Berkeley Campus, Publication No. 73 [http://nano.berkeley. edu/research/73nanotech.pdf]. The Department of Energy, Nanoscale Science Research Centers, updated their "Approach to nanomaterial ES\&H" in May 2008, as Revision 3a [http://orise.orau.gov/ihos/nanotechnology/files/NSRCMay12.pdf]. The Institute de recherche Robert-Sauvé en santé et en securité du travail (IRSST) published "Health Effects of Nanoparticles" [http://www. irsst.qc.ca/files/documents/PubIRSST/R-469.pdf].

The Environmental Health and Safety office of Massachusetts Institute of Technology prepared "Nanomaterials Toxicity", which is available at [http://ehs.mit.edu/ site/content/nanomaterials-toxicity]. NIOSH has made available "Approaches to Safe Nanotechnology. Managing the Health and Safety Concerns Associated with Engineered Nanomaterials" [http://www.cdc.gov/niosh/ topics/nanotech/safenano/]. The British Standards Institute prepared "Nanotechnologies - Part 2. Guide to safe handling and disposal of manufactured nanomaterials" in 2007, as their publication PD 6699-2:2007, ICS Number Code 13.100: 71.100 .99 [http://www.nanointeract. net/x/file/PD6699-2-safeHandling-Disposal.pdf]. The American Society for Testing and Materials prepared

A "Standard Guide for Handling Unbound Engineered Nanoparticles in Occupational Settings", as their publication ASTM E2535-07 [http://www.astm.org/Standards/E2535.htm]. This is a guide for use when no specific information on ENMs or toxicity is available. OSHA prepared "Occupational exposure to hazardous chemicals in laboratories", as their publication 1910.1450 [http://www.osha.gov/pls/oshaweb/owadisp. show_document?p_table=standards\&p_id=10106]. This guidance is designed for lab scale (i.e., not industrial) workers.

The Center for High-Rate Nanomanufacturing and $\mathrm{NIOSH}$ are preparing a guide to safe practices for working with nanomaterials that is anticipated to be released in early 2011.

Some websites that have considerable information on nanoscale materials are Nano Safe at [http://www. nanosafe.org], The International Council on Nanotechnology (ICON) [http://icon.rice.edu/], and "The
GoodNanoGuide" [http://goodnanoguide.org/tiki-index. php?page=HomePage].

\section{Conclusions}

An extensive variety of ENMs has been created. ENMs have already been utilized in many products and much more extensive use is anticipated in the future. There are reports of toxicity following in vitro and in vivo exposure to many ENMs, albeit often after very high doses, and generally lacking dose-response assessment. There is a small amount of exposure assessment information, and a paucity of information required for a risk characterization. Until more research and workplace monitoring information becomes available to refine the current knowledge of ENM risks, good workplace practices and guidelines based on ultrafine materials are guiding the occupational safety and health practices in working with ENMs.

\section{Appendix 1. Some good workplace practices}

- Post signs indicating potential hazards, PPE requirements, and administrative controls at entrances to areas where ENMs are handled.

- Use appropriate PPE as a precaution whenever failure of a control, such as an engineering control, could result in ENM exposure, or ensure that engineering controls notify workers (e.g., alarms) when equipment malfunctions. Appropriate clothing and PPE generally includes closed-toed shoes, long pants without cuffs, long-sleeved shirt, laboratory coat, nitrile gloves, eye protection and perhaps a respirator, e.g., a half-mask P-100 or one that provides a higher level of protection, as appropriate to the ENM.

- Transfer ENMs between workstations in closed, labeled containers.

- Avoid handling ENMs in the open air in a 'free particle" state.

- Store dispersible ENMs, suspended in liquids or in a dry particle form, in closed (tightly sealed) containers whenever possible.

- Clean work areas potentially contaminated with ENMs at the end of each work shift, at a minimum, using either a HEPA-filtered vacuum cleaner or wet wiping methods. Do not dry sweep or use compressed air.

- Consider the use of disposable absorbent bench top coverings and laboratory coats.

- Place sticky floor mat at exit.

- Provide facilities for hand-washing, showering and changing clothes

Prohibit food, beverages and smoking in the work area. 


\section{Acknowledgements}

The authors gratefully acknowledge the financial support for nanoscale research provided by US EPA STAR Grant RD-833772. The authors thank Matt H. Hazzard and Robin L. Jones, University of Kentucky Teaching \& Academic Support Center, for preparing Figures 1, 2, 3, 4, and 5 and Drs. Ronald E. Shaffer, NIOSH, and William K. Boyes, EPA, for their helpful comments on a prior version of this review, and an anonymous journal reviewer whose extensive comments surely improved this manuscript. This manuscript has been reviewed by the National Health and Environmental Effects Research Laboratory and approved for publication. Approval does not signify that the contents reflect the views of the Agency, nor does mention of trade names or commercial products constitute endorsement or recommendation for use.

\section{Author details}

'Department of Pharmaceutical Sciences, College of Pharmacy and Graduate Center for Toxicology, University of Kentucky, Lexington, KY, 40536-0082, USA. ${ }^{2}$ Toxicity Assessment Division, National Health and Environmental Effects Research Laboratory, U.S. Environmental Protection Agency, Research Triangle Park NC, 27711, USA.

\section{Authors' contributions}

RAY initiated this review and created a draft of the manuscript that was discussed with RCM. RCM provided significant guidance on the structure of the review and its content, wrote the Risk Assessment/Risk Management framework section, integrated that section with the rest of the review, and provided much editorial guidance as RAY and RCM re-wrote and finalized the review. Both authors contributed to the revision of the review, responding to the reviewers' comments. Both authors read and approved the final manuscript.

\section{Competing interests}

The authors declare that they have no competing interests.

Received: 8 October 2010 Accepted: 21 March 2011

Published: 21 March 2011

\section{References}

1. Oberdörster G, Oberdörster E, Oberdörster J: Nanotoxicology: an emerging discipline evolving from studies of ultrafine particles. Environ Health Perspect 2005, 113:823-839.

2. Stone V, Nowack B, Baun A, van den Brink N, Kammer F, Dusinska M, Handy R, Hankin S, Hassellov M, Joner E, Fernandes TF: Nanomaterials for environmental studies: classification, reference material issues, and strategies for physico-chemical characterisation. Sci Total Environ 2010, 408:1745-1754

3. Oberdörster G: Safety assessment for nanotechnology and nanomedicine: concepts of nanotoxicology. J Int Med 2009, 267:89-105.

4. Grieger KD, Hansen SF, Baun A: The known unknowns of nanomaterials: describing and characterizing uncertainty within environmental, health and safety risks. Nanotoxicology 2009, 3:222-233.

5. Bergamaschi E: Occupational exposure to nanomaterials: present knowledge and future development. Nanotoxicology 2009, 3:194-201

6. Hristozov D, Malsch I: Hazards and risks of engineered nanoparticles for the environment and human health. Sustainability 2009, 1:1161-1194.

7. Savolainen K, Alenius H, Norppa H, Pylkkanen L, Tuomi T, Kasper G: Risk assessment of engineered nanomaterials and nanotechnologies-a review. Toxicology 2010, 269:92-104.

8. Nanoscale Science, Engineering and Technology (NSET) Subcommittee of the U.S. National Science and Technology Council (NSTC): Nanotechnology definition, National Science Foundation. [http://www.nsf.gov/crssprgm/ nano/reports/omb_nifty50.jsp].

9. BSi (British Standards): Terminology for nanomaterials. Publicly available specification, PAS 2007, 136:2007.

10. The Royal Academy of Engineering, The Royal Society: Nanoscience and nanotechnologies: opportunities and uncertainties. 2004 [http://www. nanotec.org.uk/report/Nano\%20report\%202004\%20fin.pdf].

11. Donaldson K, Stone V, MacNee W: The toxicology of ultrafine particles. Particulate Matter 1999, 115-129.

12. Duffin R, Mills NL, Donaldson K: Nanoparticles-a thoracic toxicology perspective. Yonsei Med J 2007, 48:561-572.
13. U.S. Environmental Protection Agency, Office of Research and Development: Air quality criteria for particulate matter. Washington, D.C; 1994, 3 600/P-95-001CF.

14. Cao G: Nanostructures \& nanomaterials. Synthesis, properties \& applications London: Imperial College Press; 2004.

15. etc group (Action group on erosion, technology and concentration): Nanotech: Unpredictable and Un-Regulated. [http://www.etcgroup.org/ en/node/96].

16. TA-SWISS, the Centre for Technology Assessment: Swiss survey reveals public have a fear of nanotechnology. 2006 [http://www.azonano.com/ News.asp?NewsID=3484].

17. Singer N: New Products Bring Side Effect: Nanophobia. The New York Times - New York Edition 2008 [http://www.nytimes.com/2008/12/04/ fashion/04skin.html?pagewanted=1\&_r=2], E1, December 3 .

18. Alleyne R: Food manufacturers fear nanotechnology backlash. The Telegraph 2010 [http://www.telegraph.co.uk/health/healthnews/6946800/ Food-manufacturers-fear-nanotechnology-backlash.html].

19. Organic Consumers Association: Groups demand EPA stop sale of 200+ potentially dangerous nano-silver products. 1195 [http://www. organicconsumers.org/articles/article_11955.cfm].

20. Schulte P: Overview. Presentation: Nanomaterials and worker health. Medical surveillance, exposure registries, and epidemiologic research Keystone, CO, 2010.

21. Environment Directorate, Joint Meeting of the Chemicals Committee and the Working Party on Chemicals, Pesticides and Biotechnology, OECD:: List of manufactured nanomaterials and list of endpoints for phase one of the OECD testing programme. Series on the safety of manufactured nanomaterials 2008, 13, ENV/JM/MONO(2008).

22. Kagan VE, Shi J, Feng W, Shvedova AA, Fadeel B: Fantastic voyage and opportunities of engineered nanomaterials: what are the potential risks of occupational exposures? J Occup Environ Med 2010, 52:943-946.

23. Yokel RA, Florence RL, Unrine JM, Tseng MT, Graham UM, Wu P, Grulke EA, Sultana R, Hardas SS, Butterfield DA: Biodistribution and oxidative stress effects of a systemically-introduced commercial ceria engineered nanomaterial. Nanotoxicology 2009, 3:234-248.

24. Warheit DB, Sayes CM, Reed KL: Nanoscale and fine zinc oxide particles: can in vitro assays accurately forecast lung hazards following inhalation exposures? Environ Sci Technol 2009, 43:7939-7945.

25. Liu X, Guo L, Morris D, Kane AB, Hurt RH: Targeted removal of bioavailable metal as a detoxification strategy for carbon nanotubes. Carbon 2008, 46:489-500.

26. O'Brien N, Cummins E: Recent developments in nanotechnology and risk assessment strategies for addressing public and environmental health concerns. Human Ecolog Risk Assess 2008, 14:568-592.

27. Hansen SF, Michelson ES, Kamper A, Borling P, Stuer-Lauridsen F, Baun A: Categorization framework to aid exposure assessment of nanomaterials in consumer products. Ecotoxicology 2008, 17:438-447.

28. Woodrow Wilson International Center for Scholars: The Project on Emerging Nanotechnologies. 2011 [http://www.nanotechproject.org/ inventories/].

29. Schubauer-Berigan M, Dahm M, Yencken M: Engineered carbonaceous nanomaterials manufacturers in the United States: workforce size, characteristics and feasibility of epidemiologic studies. J Occup Environ Med 2011.

30. Dahm M, Yencken M, Schubauer-Berigan M: Exposure control strategies in the carbonaceous nanomaterial industry. J Occup Environ Med 2011.

31. Roco MC: International perspective on government nanotechnology funding in 2005. J Nanopart Res 2005, 7:1-9.

32. Maynard AD: Nanotechnology: The Next Big Thing, or Much Ado about Nothing? Ann Occup Hyg 2006, 51:1-12.

33. President's Council of Advisors on Science and Technology: The National Nanotechnology Initiative at five years. Washington, D.C; 2005 [http://www.nano.gov/FINAL_PCAST_NANO_REPORT.pdf].

34. National Nanotechnology Initiative Investments by Agency. 2009 [http://www.nano.gov/NNI_Investments by Agency PCA_2001_2010.xls].

35. United Nations Educational, Scientific and Cultural Organization (UNESCO) The ethics and politics of nanotechnology. 2006 [http://unesdoc.unesco. org/images/0014/001459/145951e.pdf].

36. Druckman JN, Bolsen T: Framing, motivated reasoning, and opinions about emergent technologies. J Communication. 
37. European Commission: REACH and nanomaterials. 2010 [http://ec.europa. eu/enterprise/sectors/chemicals/reach/nanomaterials/index_en.htm].

38. Chen H, Roco MC, Li X, Lin Y: Trends in nanotechnology patents. Nat Nanotechnol 2008, 3:123-125.

39. NRC Committee on the Institutional Means for Assessment of Risks to Public Health, National Research Council: Risk Assessment in the Federal Government: Managing the Process. 1983, 191.

40. Gioacchino MD, Verna N, Gornati R, Sabbioni E, Bernardini G: Metal nanoparticle health risk assessment. In Nanotoxicity. Edited by: Sahu SC, Casciano DA. West Sussex, United Kingdom: Wiley; 2009:519-541.

41. Choi JY, Ramachandran G, Kandlikar M: The impact of toxicity testing costs on nanomaterial regulation. Environ Sci Technol 2009, 43:3030-3034

42. Rushton EK, Jiang J, Leonard SS, Eberly S, Castranova V, Biswas P, Elder A, Han X, Gelein R, Finkelstein J, Oberdörster G: Concept of assessing nanoparticle hazards considering nanoparticle dosemetric and chemical/ biological response metrics. J Toxicol Environ Health A 2010, 73:445-461.

43. Jones $C F$, Grainger DW: In vitro assessments of nanomaterial toxicity. Adv Drug Deliv Rev 2009, 61:438-456.

44. Fischer HC, Chan WC: Nanotoxicity: the growing need for in vivo study. Curr Opin Biotechnol 2007, 18:565-571.

45. Oberdörster G, Maynard A, Donaldson K, Castranova V, Fitzpatrick J, Ausman K, Carter J, Karn B, Kreyling W, Lai D, et al: Principles for characterizing the potential human health effects from exposure to nanomaterials: Elements of a screening strategy. Part Fibre Toxicol 2005, 2:35

46. Shaw SY, Westly EC, Pittet MJ, Subramanian A, Schreiber SL, Weissleder R: Perturbational profiling of nanomaterial biologic activity. Proc Natl Acad Sci USA 2008, 105:7387-7392.

47. Tervonen T, Linkov I, Figueira JR, Steevens J, Chappell M: Risk-based classification system of nanomaterials. J Nanopart Res 2009, 11:757-766.

48. Zalk DM, Paik SY, Swuste P: Evaluating the Control Banding Nanotool: a qualitative risk assessment method for controlling nanoparticle exposure. J Nanopart Res 2009, 11:1685-1704.

49. Saliner AG, Burello E, Worth A: Review of computational approaches for predicting the physicochemical and biological properties of nanoparticles. JRC Sci Tech Reports EUR 2008, 23974 - 2009

50. Poater A, Gallegos Saliner A, Sola M, Cavallo L, Worth AP: Computational methods to predict the reactivity of nanoparticles through structureproperty relationships. Expert Opin Drug Deliv 2010, 7:295-305.

51. Brouwer D: Exposure to manufactured nanoparticles in different workplaces. Toxicology 2010, 269:120-127.

52. Gurr JR, Wang $\mathrm{AS}$, Chen $\mathrm{CH}$, Jan $\mathrm{KY}$ : Ultrafine titanium dioxide particles in the absence of photoactivation can induce oxidative damage to human bronchial epithelial cells. Toxicology 2005, 213:66-73.

53. Jiang J, Oberdörster G, Elder A, Gelein R, Mercer P, Biswas P: Does nanoparticle activity depend upon size and crystal phase? Nanotoxicology 2008, 2:33-42.

54. Hackley VA, Ferraris CF: The use of nomenclature in dispersion science and technology. National Institute of Standards and Technology, Special Publication 960-3, U.S. Government Printing Office; 2001, 72

55. Seipenbusch M, Binder A, Kasper G: Temporal evolution of nanoparticle aerosols in workplace exposure. Ann Occup Hyg 2008, 52:707-716.

56. Methner M, Hodson L, Geraci C: Nanoparticle emission assessment technique (NEAT) for the identification and measurement of potential inhalation exposure to engineered nanomaterials-part A. J Occup Environ Hyg 2010, 7:127-132.

57. Pauluhn J: Multi-walled carbon nanotubes (Baytubes): approach for derivation of occupational exposure limit. Regul Toxicol Pharmacol 2010, 57:78-89.

58. Limbach LK, Li Y, Grass RN, Brunner TJ, Hintermann MA, Muller M Gunther D, Stark WJ: Oxide nanoparticle uptake in human lung fibroblasts: effects of particle size, agglomeration, and diffusion at low concentrations. Environ Sci Technol 2005, 39:9370-9376.

59. WHO/EURO, Technical Committee for Monitoring and Evaluating Airborne MMMF: Reference methods for measuring airborne man-made mineral fibres (MMMF), WHO/EURO MMMF Reference Scheme, Monitoring concentration using a phase contrast optical microscope, Determining size using a scanning electron microscope. World Health Organization, Regional Office for Europe, Copenhagen; 1985, 64.

60. Auffan M, Rose J, Bottero JY, Lowry GV, Jolivet JP, Wiesner MR: Towards a definition of inorganic nanoparticles from an environmental, health and safety perspective. Nature Nanotechnol 2009, 4:634-641.
61. Chithrani BD, Ghazani AA, Chan WC: Determining the size and shape dependence of gold nanoparticle uptake into mammalian cells. Nano Lett 2006, 6:662-668.

62. Nel AE, Madler L, Velegol D, Xia T, Hoek EM, Somasundaran P, Klaessig F, Castranova $\mathrm{V}$, Thompson M: Understanding biophysicochemical interactions at the nano-bio interface. Nat Mater 2009, 8:543-557.

63. Raffa V, Vittorio O, Riggio C, Cuschieri A: Progress in nanotechnology for healthcare. Minim Invasive Ther Allied Technol 2010, 19:127-135.

64. Lundqvist M, Stigler J, Elia G, Lynch I, Cedervall T, Dawson KA: Nanoparticle size and surface properties determine the protein corona with possible implications for biological impacts. Proc Natl Acad Sci USA 2008, 105:14265-14270.

65. Belgorodsky B, Drug E, Fadeev L, Hendler N, Mentovich E, Gozin M: Mucin complexes of nanomaterials: first biochemical encounter. Small 2010, 6:262-269

66. Deng ZJ, Mortimer G, Schiller T, Musumeci A, Martin D, Minchin RF: Differential plasma protein binding to metal oxide nanoparticles. Nanotechnology 2009, 20:455101/1-455101/9.

67. Borm PJA, Robbins D, Haubold S, Kuhlbusch T, Fissan H, Donaldson KS, Roel , Stone V, Kreyling W, Lademann J, Krutmann J, et al: The potential risks of nanomaterials: A review carried out for ECETOC. Part Fibre Toxicol 2006, 3:35.

68. Liu X, Tao H, Yang K, Zhang S, Lee ST, Liu Z: Optimization of surface chemistry on single-walled carbon nanotubes for in vivo photothermal ablation of tumors. Biomaterials 2010, 32:144-151.

69. Huang C, Neoh KG, Wang L, Kang ET, Shuter B: Magnetic nanoparticles for magnetic resonance imaging: modulation of macrophage uptake by controlled PEGylation of the surface coating. J Mat Chem 2010, 39:8512-8520.

70. Fernández-Argüelles MT, Yakovlev A, Sperling RA, Luccardini C, Gaillard S, Medel AS, Mallet JM, Brochon JC, Feltz A, Oheim M, Parak WJ: Synthesis and characterization of polymer-coated quantum dots with integrated acceptor dyes as FRET-based nanoprobes. Nano Lett 2007, 7:2613-2617.

71. Stuart D, Lobenberg R, Ku T, Azarmi S, Ely L, Roa W, Prenner EJ: Biophysical investigation of nanoparticle interactions with lung surfactant model systems. J Biomed Nanotechnol 2006, 2:245-252

72. Harishchandra RK, Saleem M, Galla HJ: Nanoparticle interaction with model lung surfactant monolayers. J Royal Soc, Interface 2010, 7:S15-S26.

73. ICRP: International Commission on Radiological Protection. Human respiratory tract model for radiological protection. Ann ICRP 1994, 120, Publication No. 66

74. Segal RA, Martonen TB, Kim CS, Shearer M: Computer simulations of particle deposition in the lungs of chronic obstructive pulmonary disease patients. Inhal Toxicol 2002, 14:705-720.

75. Sturm R, Hofmann W: Stochastic simulation of alveolar particle deposition in lungs affected by different types of emphysema. J Aerosol Med 2004, 17:357-372.

76. Bodian D, Howe HA: Experimental studies on intraneuronal spread of poliomyelitis virus. Bull Johns Hopkins Hosp 1941, 69:248-267.

77. Bodian D, Howe HA: The rate of progression of poliomyelitis virus in nerves. Bull Johns Hopkins Hosp 1941, 69:79-85.

78. De Lorenzo A: The olfactory neuron and the blood-brain barrier. In Taste and smell in vertebrates. Edited by: Wolstenholme G, Knight J. London: Churchhill: 1970:151-176.

79. Oberdörster G, Sharp Z, Atudorei V, Elder A, Gelein R, Kreyling W, Cox C: Translocation of inhaled ultrafine particles to the brain. Inhal Toxicol 2004, 16:437-445.

80. Elder A, Gelein R, Silva V, Feikert T, Opanashuk L, Carter J, Potter R, Maynard A, Ito Y, Finkelstein J, Oberdörster G: Translocation of inhaled ultrafine manganese oxide particles to the central nervous system. Environ Health Perspect 2006, 114:1172-1178.

81. Tan MH, Commens CA, Burnett L, Snitch PJ: A pilot study on the percutaneous absorption of microfine titanium dioxide from sunscreens. Australasian J Dermatol 1996, 37:185-187.

82. Filipe P, Silva JN, Silva R, Cirne de Castro JL, Marques Gomes M, Alves LC, Santus R, Pinheiro T: Stratum corneum is an effective barrier to $\mathrm{TiO}_{2}$ and $\mathrm{ZnO}$ nanoparticle percutaneous absorption. Skin Pharmacol Physiol 2009, 22:266-275.

83. Gamer AO, Leibold E, van Ravenzwaay B: The in vitro absorption of microfine zinc oxide and titanium dioxide through porcine skin. Toxicology in Vitro 2006, 20:301-307. 
84. Pflucker F, Wendel V, Hohenberg H, Gartner E, Will T, Pfeiffer S, Wepf R, Gers-Barlag H: The human stratum corneum layer: an effective barrier against dermal uptake of different forms of topically applied micronised titanium dioxide. Skin Pharmacol Appl Skin Physiol 2001, 14(Suppl 1):92-97.

85. Pinheiro T, Pallon J, Alves LC, Veríssimo A, Filipe P, Silva JN, Silva R: The influence of corneocyte structure on the interpretation of permeation profiles of nanoparticles across skin. Nucl Instrument Meth Physics Res $B$ 260:119-123

86. Schulz J, Hohenberg H, Pflucker F, Gartner E, Will T, Pfeiffer S, Wepf R, Wendel V, Gers-Barlag H, Wittern KP: Distribution of sunscreens on skin. Adv Drug Deliv Rev 2002, 54(Suppl 1):S157-163.

87. Popov A, Zhao X, Zvyagin A, Lademann J, Roberts M, Sanchez W, Priezzhev A, Myllylae $\mathrm{R}: \mathrm{ZnO}$ and $\mathrm{TiO}_{2}$ particles: a study on nanosafety and photoprotection. Proc SPIE 2010, 7715:77153G/1-77153G/7.

88. Cross SE, Innes B, Roberts MS, Tsuzuki T, Robertson TA, McCormick P: Human skin penetration of sunscreen nanoparticles: in-vitro assessment of a novel micronized zinc oxide formulation. Skin Pharmacol Physiol 2007, 20:148-154.

89. Baroli B, Ennas MG, Loffredo F, Isola M, Pinna R, Lopez-Quintela MA: Penetration of metallic nanoparticles in human full-thickness skin. $J$ Invest Dermatol 2007, 127:1701-1712.

90. Lademann J, Weigmann H, Rickmeyer C, Barthelmes H, Schaefer H, Mueller G, Sterry W: Penetration of titanium dioxide microparticles in a sunscreen formulation into the horny layer and the follicular orifice. Skin Pharmacol Appl Skin Physiol 1999, 12:247-256.

91. Lademann J, Richter H, Teichmann A, Otberg N, Blume-Peytavi U, Luengo J, Weiss B, Schaefer UF, Lehr CM, Wepf R, Sterry W: Nanoparticles-an efficient carrier for drug delivery into the hair follicles. Eur J Pharm Biopharm 2007, 66:159-164.

92. Mortensen LJ, Oberdörster G, Pentland AP, Delouise LA: In vivo skin penetration of quantum dot nanoparticles in the murine model: the effect of UVR. Nano Lett 2008, 8:2779-2787.

93. Gopee NV, Roberts DW, Webb P, Cozart CR, Siitonen PH, Warbritton AR, Yu WW, Colvin VL, Walker NJ, Howard PC: Migration of intradermally injected quantum dots to sentinel organs in mice. Toxicol Sci 2007, 98:249-257.

94. Wakefield G, Lipscomb S, Holland E, Knowland J: The effects of manganese doping on UVA absorption and free radical generation of micronised titanium dioxide and its consequences for the photostability of UVA absorbing organic sunscreen components. Photochem Photobiol Sci 2004, 3:648-652.

95. Tinkle SS, Antonini JM, Rich BA, Roberts JR, Salmen R, DePree K, Adkins EJ: Skin as a route of exposure and sensitization in chronic beryllium disease. Environ Health Perspect 2003, 111:1202-1208.

96. Rouse JG, Yang J, Ryman-Rasmussen JP, Barron AR, Monteiro-Riviere NA: Effects of mechanical flexion on the penetration of fullerene amino acid-derivatized peptide nanoparticles through skin. Nano Lett 2007, 7:155-160.

97. Sadrieh N, Wokovich AM, Gopee NV, Zheng J, Haines D, Parmiter D, Siitonen PH, Cozart CR, Patri AK, MCNeil SE, et al: Lack of significant dermal penetration of titanium dioxide from sunscreen formulations containing nano- and submicron-size $\mathrm{TiO}_{2}$ particles. Toxicol Sci 2010, 115:156-166.

98. Murray AR, Kisin E, Leonard SS, Young SH, Kommineni C, Kagan VE, Castranova V, Shvedova AA: Oxidative stress and inflammatory response in dermal toxicity of single-walled carbon nanotubes. Toxicology 2009, 257:161-171

99. Xia XR, Monteiro-Riviere NA, Riviere JE: Skin penetration and kinetics of pristine fullerenes (C60) topically exposed in industrial organic solvents. Toxicol Appl Pharmacol 2010, 242:29-37.

100. Hoet PH, Bruske-Hohlfeld I, Salata OV: Nanoparticles - known and unknown health risks. J Nanobiotechnol 2004, 2:12.

101. Nwokolo CU, Lewin JF, Hudson M, Pounder RE: Transmucosal penetration of bismuth particles in the human stomach. Gastroenterol 1992, 102:163-167.

102. Hillery AM, Jani PU, Florence AT: Comparative, quantitative study of lymphoid and non-lymphoid uptake of $60 \mathrm{~nm}$ polystyrene particles. J Drug Target 1994, 2:151-156.

103. Jani PU, Florence AT, MCCarthy DE: Further histological evidence of the gastrointestinal absorption of polystyrene nanospheres in the rat. Int $J$ Pharmaceut 1992, 84:245-252.
104. Jani P, Halbert GW, Langridge J, Florence AT: Nanoparticle uptake by the rat gastrointestinal mucosa: quantitation and particle size dependency. J Pharm Pharmacol 1990, 42:821-826.

105. Jani PU, Nomura T, Yamashita F, Takakura Y, Florence AT, Hashida M: Biliary excretion of polystyrene microspheres with covalently linked FITC fluorescence after oral and parenteral administration to male Wistar rats. J Drug Target 1996, 4:87-93.

106. Hillyer JF, Albrecht RM: Gastrointestinal persorption and tissue distribution of differently sized colloidal gold nanoparticles. J Pharm Sci 2001, 90:1927-1936.

107. Hendley JO, Wenzel RP, Gwaltney JM: Transmission of rhinovirus colds by self-inoculation. NEJM 1973, 288:1361-1364.

108. Zimmer A, Kreuter J, Robinson JR: Studies on the transport pathway of PBCA nanoparticles in ocular tissues. J Microencapsul 1991, 8:497-504.

109. Slovic P: Perception of risk. Science 1987, 236:280-285.

110. MacGregor D, Slovic P, Malmfors T: "How exposed is exposed enough?" Lay inferences about chemical exposure. Risk Analysis 1999, 19:649-659.

111. Madl AK, Pinkerton KE: Health effects of inhaled engineered and incidental nanoparticles. Crit Rev Toxicol 2009, 39:629-658.

112. Priester JH, Stoimenov PK, Mielke RE, Webb SM, Ehrhardt C, Zhang JP, Stucky GD, Holden PA: Effects of soluble cadmium salts versus $\mathrm{CdSe}$ quantum dots on the growth of planktonic Pseudomonas aeruginosa. Environ Sci Technol 2009, 43:2589-2594.

113. Xia T, Kovochich M, Liong M, Madler L, Gilbert B, Shi H, Yeh Jl, Zink Jl, Nel AE: Comparison of the mechanism of toxicity of zinc oxide and cerium oxide nanoparticles based on dissolution and oxidative stress properties. ACS Nano 2008, 2:2121-2134.

114. Wong SW, Leung PT, Djurisic AB, Leung KM: Toxicities of nano zinc oxide to five marine organisms: influences of aggregate size and ion solubility. Anal Bioanal Chem 2010, 396:609-618.

115. Heinrich U, Fuhst R, Rittinghausen S, Creutzenberg O, Bellmann B, Koch W Levsen : Chronic inhalation exposure of Wistar rats and two different strains of mice to diesel engine exhaust, carbon black, and titanium dioxide. Inhal Toxicol 1995, 7:533-556.

116. Lam CW, James JT, McCluskey R, Hunter RL: Pulmonary toxicity of singlewall carbon nanotubes in mice 7 and 90 days after intratracheal instillation. Toxicol Sci 2004, 77:126-134.

117. Kelly RJ: Occupational medicine implications of engineered nanoscale particulate matter. J Chem Health Safety 2009, 16:24-39.

118. Erdely A, Hulderman T, Salmen R, Liston A, Zeidler-Erdely PC, SchweglerBerry D, Castranova V, Koyama S, Kim YA, Endo M, Simeonova PP: Crosstalk between lung and systemic circulation during carbon nanotube respiratory exposure. Potential biomarkers. Nano Lett 2009, 9:36-43.

119. Ryman-Rasmussen JP, Tewksbury EW, Moss OR, Cesta MF, Wong BA, Bonner JC: Inhaled multiwalled carbon nanotubes potentiate airway fibrosis in murine allergic asthma. Am J Respir Cell Mol Biol 2009, 40:349-358.

120. Lindberg HK, Falck GC, Suhonen S, Vippola M, Vanhala E, Catalan J, Savolainen K, Norppa H: Genotoxicity of nanomaterials: DNA damage and micronuclei induced by carbon nanotubes and graphite nanofibres in human bronchial epithelial cells in vitro. Toxicol Lett 2009, 186:166-173.

121. Li JG, Li WX, Xu JY, Cai XQ, Liu RL, Li YJ, Zhao QF, Li QN: Comparative study of pathological lesions induced by multiwalled carbon nanotubes in lungs of mice by intratracheal instillation and inhalation. Environ Toxicol 2007, 22:415-421.

122. Monteiller C, Tran L, MacNee W, Faux S, Jones A, Miller B, Donaldson K: The pro-inflammatory effects of low-toxicity low-solubility particles, nanoparticles and fine particles, on epithelial cells in vitro: the role of surface area. Occup Environ Med 2007, 64:609-615.

123. Totsuka Y, Higuchi T, Imai T, Nishikawa A, Nohmi T, Kato T, Masuda S, Kinae N, Hiyoshi K, Ogo S, et al: Genotoxicity of nano/microparticles in in vitro micronuclei, in vivo comet and mutation assay systems. Part Fibre Toxicol 2009, 6:23.

124. Takagi A, Hirose A, Nishimura T, Fukumori N, Ogata A, Ohashi N, Kitajima S, Kanno J: Induction of mesothelioma in $\mathrm{p} 53+/$ - mouse by intraperitoneal application of multi-wall carbon nanotube. J Toxicol Sci 2008, 33:105-116.

125. Poland CA, Duffin R, Kinloch I, Maynard A, Wallace WA, Seaton A, Stone V, Brown S, Macnee W, Donaldson K: Carbon nanotubes introduced into the abdominal cavity of mice show asbestos-like pathogenicity in a pilot study. Nat Nanotechnol 2008, 3:423-428. 
126. Muller J, Delos M, Panin N, Rabolli V, Huaux F, Lison D: Absence of carcinogenic response to multiwall carbon nanotubes in a 2-year bioassay in the peritoneal cavity of the rat. Toxicol Sci 2009, 110:442-448,

127. Park EJ, Choi J, Park YK, Park K: Oxidative stress induced by cerium oxide nanoparticles in cultured BEAS-2B cells. Toxicology 2008, 245:90-100.

128. Park EJ, Yi J, Chung KH, Ryu DY, Choi J, Park K: Oxidative stress and apoptosis induced by titanium dioxide nanoparticles in cultured BEAS2B cells. Toxicol Lett 2008, 180:222-229.

129. Lin W, Huang YW, Zhou XD, Ma Y: Toxicity of cerium oxide nanoparticles in human lung cancer cells. Int J Toxicol 2006, 25:451-457.

130. Kim IS, Baek M, Choi SJ: Comparative cytotoxicity of $\mathrm{Al}_{2} \mathrm{O}_{3}, \mathrm{CeO}_{2}, \mathrm{TiO}_{2}$ and ZnO nanoparticles to human lung cells. J Nanosci Nanotechnol 2010, 10:3453-3458

131. Long TC, Saleh N, Tilton RD, Lowry GV, Veronesi B: Titanium dioxide (P25) produces reactive oxygen species in immortalized brain microglia (BV2): Implications for nanoparticle neurotoxicity. Environ Sci Technol 2006, 40:4346-4352.

132. Hardas SS, Butterfield DA, Sultana R, Tseng MT, Dan M, Florence RL, Unrine JM, Graham UM, Wu P, Grulke EA, Yokel RA: Brain distribution and toxicological evaluation of a systemically delivered engineered nanoscale ceria. Toxicol Sci 2010, 116:562-576.

133. Samberg ME, Oldenburg SJ, Monteiro-Riviere NA: Evaluation of silver nanoparticle toxicity in skin in vivo and keratinocytes in vitro. Environ Health Perspect 2010, 118:407-413.

134. Mohan N, Chen CS, Hsieh HH, Wu YC, Chang HC: In vivo imaging and toxicity assessments of fluorescent nanodiamonds in Caenorhabditis elegans. Nano Lett 2010, 10:3692-3699.

135. Truong L, Harper SL, Tanguay RL: Evaluation of embryotoxicity using the zebrafish model. Methods Mol Biol 691:271-279.

136. Bar-llan O, Albrecht RM, Fako VE, Furgeson DY: Toxicity assessments of multisized gold and silver nanoparticles in zebrafish embryos. Small 2009, 5:1897-1910.

137. Wittmaack K: In search of the most relevant parameter for quantifying lung inflammatory response to nanoparticle exposure: particle number, surface area, or what? Environ Health Perspect 2007, 115:187-194.

138. Duffin R, Tran L, Brown D, Stone V, Donaldson K: Proinflammogenic effects of low-toxicity and metal nanoparticles in vivo and in vitro: highlighting the role of particle surface area and surface reactivity. Inhal Toxicol 2007, 19:849-856.

139. Waters KM, Masiello LM, Zangar RC, Tarasevich BJ, Karin NJ, Quesenberry RD, Bandyopadhyay S, Teeguarden JG, Pounds JG, Thrall BD: Macrophage responses to silica nanoparticles are highly conserved across particle sizes. Toxicol Sci 2009, 107:553-569.

140. Ma L, Liu J, Li N, Wang J, Duan Y, Yan J, Liu H, Wang H, Hong F: Oxidative stress in the brain of mice caused by translocated nanoparticulate $\mathrm{TiO}_{2}$ delivered to the abdominal cavity. Biomaterials 2010, 31:99-105.

141. Pauluhn J: Subchronic 13-week inhalation exposure of rats to multiwalled carbon nanotubes: toxic effects are determined by density of agglomerate structures, not fibrillar structures. Toxicol Sci 2010, 113:226-242.

142. Dutta D, Sundaram SK, Teeguarden JG, Riley BJ, Fifield LS, Jacobs JM, Addleman SR, Kaysen GA, Moudgil BM, Weber TJ: Adsorbed proteins influence the biological activity and molecular targeting of nanomaterials. Toxicol Sci 2007, 100:303-315.

143. Muller J, Huaux F, Moreau N, Misson P, Heilier JF, Delos M, Arras M, Fonseca A, Nagy JB, Lison D: Respiratory toxicity of multi-wall carbon nanotubes. Toxicol Appl Pharmacol 2005, 207:221-231.

144. Tsai SJ, Hofmann M, Hallock M, Ada E, Kong J, Ellenbecker M: Characterization and evaluation of nanoparticle release during the synthesis of single-walled and multiwalled carbon nanotubes by chemical vapor deposition. Environ Sci Technol 2009, 43:6017-6023.

145. Bailey MR, Fry FA, James AC: The long-term clearance kinetics of insoluble particles from the human lung. Ann Occup Hyg 1982, 26:273-290.

146. O'Neill LA: Immunology. How frustration leads to inflammation. Science 2008, 320:619-620

147. Hamilton RF, Wu N, Porter D, Buford M, Wolfarth M, Holian A: Particle length-dependent titanium dioxide nanomaterials toxicity and bioactivity. Part Fibre Toxicol 2009, 6:35.

148. Ryman-Rasmussen JP, Cesta MF, Brody AR, Shipley-Phillips JK, Everitt J, Tewksbury EW, Moss OR, Wong BA, Dodd DE, Andersen ME, Bonner JC:
Inhaled carbon nanotubes reach the subpleural tissue in mice. Nat Nanotechnol 2009, 4:747-751.

149. Porter DW, Hubbs AF, Mercer RR, Wu N, Wolfarth MG, Sriram K, Leonard S, Battelli L, Schwegler-Berry D, Friend S, et al: Mouse pulmonary dose- and time course-responses induced by exposure to multi-walled carbon nanotubes. Toxicology 2009, 269:136-147.

150. Oberdörster G, Sharp Z, Atudorei V, Elder A, Gelein R, Lunts A, Kreyling W, Cox C: Extrapulmonary translocation of ultrafine carbon particles following whole-body inhalation exposure of rats. J Toxicol Environ Health A 2002, 65:1531-1543.

151. Kreyling WG, Semmler M, Erbe F, Mayer P, Takenaka S, Schulz $H$, Oberdörster $G$, Ziesenis A: Translocation of ultrafine insoluble iridium particles from lung epithelium to extrapulmonary organs is size dependent but very low. J Toxicol Environ Health A 2002, 65:1513-1530.

152. Tsuchiya T, Oguri I, Yamakoshi YN, Miyata N: Novel harmful effects of [60] fullerene on mouse embryos in vitro and in vivo. FEBS Lett 1996, 393:139-145.

153. Takeda K, Suzuki Ki, Ishihara A, Kubo-Irie M, Fujimoto R, Tabata M, Oshio S, Nihei $Y$, Ihara T, Sugamata M: Nanoparticles transferred from pregnant mice to their offspring can damage the genital and cranial nerve systems. J Health Sci 2009, 55:95-102.

154. Sakamoto Y, Nakae D, Fukumori N, Tayama K, Maekawa A, Imai K, Hirose A, Nishimura T, Ohashi N, Ogata A: Induction of mesothelioma by a single intrascrotal administration of multi-wall carbon nanotube in intact male Fischer 344 rats. J Toxicol Sci 2009, 34:65-76.

155. Chen J, Tan M, Nemmar A, Song W, Dong M, Zhang G, Li Y: Quantification of extrapulmonary translocation of intratracheal-instilled particles in vivo in rats: effect of lipopolysaccharide. Toxicology 2006, 222:195-201.

156. Biozzi G, Benacerraf B, Halpern BN: Quantitative study of the granulopectic activity of the reticulo-endothelial system. II. A study of the kinetics of the R. E. S. in relation to the dose of carbon injected; relationship between the weight of the organs and their activity. $\mathrm{Br} J$ Exp Pathol 1953, 34:441-457.

157. Schipper ML, Nakayama-Ratchford N, Davis CR, Kam NW, Chu P, Liu Z, Sun X, Dai H, Gambhir SS: A pilot toxicology study of single-walled carbon nanotubes in a small sample of mice. Nat Nanotechnol 2008, 3:216-221.

158. Sadauskas E, Jacobsen NR, Danscher G, Stoltenberg M, Vogel U, Larsen A, Kreyling W, Wallin H: Biodistribution of gold nanoparticles in mouse lung following intratracheal instillation. Chem Cent J 2009, 3:16.

159. Yokel RA, Florence RMD, Unrine J, Tseng MT, Graham UM, Sultana R, Hardas SBDA, Wu P, Grulke EA: Safety/toxicity assessment of ceria (a model engineered NP) to the brain. Presentation: Interagency Nanotechnology Implications Grantees Workshop-EPA, NSF, NIEHS, NIOSH, and DOE; November 9-11 Las Vegas, NV; 2009.

160. Symens N, Walzack R, Demeester J, Mattaj I, De Smedt SC, Remaut K: Nuclear inclusion of inert and chromatin-targeted polystyrene spheres and plasmid DNA containing nanoparticles. J Control Release 2010, 148: e96-e98.

161. Bhojani MS, Van Dort M, Rehemtulla A, Ross BD: Targeted imaging and therapy of brain cancer using theranostic nanoparticles. Mol Pharm 2010, 7:1921-1929.

162. Wong HL, Chattopadhyay N, Wu XY, Bendayan R: Nanotechnology applications for improved delivery of antiretroviral drugs to the brain. Adv Drug Deliv Rev 2009, 62:503-517.

163. Yang $H$ : Nanoparticle-mediated brain-specific drug delivery, imaging, and diagnosis. Pharm Res 2010, 27:1759-1771.

164. Silva GA: Nanotechnology applications and approaches for neuroregeneration and drug delivery to the central nervous system. Ann N Y Acad Sci 2010, 1199:221-230

165. Lockman PR, Koziara JM, Mumper RJ, Allen DD: Nanoparticle surface charges alter blood-brain barrier integrity and permeability. J Drug Targeting 2004, 12:635-641.

166. European Parliament, Policy Department Economic and Scientific Policy: Nanomaterials in consumer products, Availability on the European market and adequacy of the regulatory framework. 2006 [http://www. europarl.europa.eu/comparl/envi/pdf/externalexpertise/ nanomaterials_in_consumer_products.pdf], RIVM/SIR Advisory report 11014 , (IP/A/ENVI/IC/2006-193). 
167. Jani P, Halbert GW, Langridge J, Florence AT: The uptake and translocation of latex nanospheres and microspheres after oral administration to rats. J Pharm Pharmacol 1989, 41:809-812.

168. Qu GB, Yuhong, Zhang, Yi , Jia, Qing, Zhang, Weidong, Yan, Bing: The effect of multiwalled carbon nanotube agglomeration on their accumulation in and damage to organs in mice. Carbon 2009, 47:2060-2069.

169. Dan M, Tseng MT, Florence RL, Tiu G, Unrine JM, Graham UM, Sultana R, Hardas SS, Helm M, Butterfield DA, et al: Short- and long-term biodistribution and oxidative stress effects of a systemically-introduced $5 \mathrm{~nm}$ ceria engineered nanomaterial. Presentation: 49th Annual Meeting of the Society of Toxicology; March 7-11 Salt Lake City, UT; 2010, Program \# 277

170. Yang K, Xing B: Adsorption of fulvic acid by carbon nanotubes from water. Environment Pollution 2009, 157:1095-1100.

171. Horie M, Nishio K, Fujita K, Endoh S, Miyauchi A, Saito Y, Iwahashi H, Yamamoto K, Murayama $\mathrm{H}$, Nakano $\mathrm{H}$, et al: Protein adsorption of ultrafine metal oxide and its Influence on cytotoxicity toward cultured cells. Chem Res Toxicol 2009, 22:543-553.

172. Barber DS, Stevens S, Wasdo S, Feswick A, Carpinone P, Denslow N, Powers K, Roberts SM: Nanoparticle size and composition affect adsorption of human plasma proteins. Presentation: 48th Annual Meeting Society of Toxicology Meeting Baltimore, MD; 2009, Program \# 860.

173. Walczyk D, Bombelli FB, Monopoli MP, Lynch I, Dawson KA: What the cell "sees" in bionanoscience. J Am Chem Soc 2010, 132:5761-5768.

174. Reddy AR, Krishna DR, Reddy YN, Himabindu V: Translocation and extra pulmonary toxicities of multi wall carbon nanotubes in rats. Toxicol Mech Meth 2010, 20:267-272

175. Schmid K, Riediker M: Use of nanoparticles in Swiss industry: A targeted survey. Environ Sci Technol 2008, 42:2253-2260

176. Shi JP, Khan AA, Harrison RM: Measurements of ultrafine particle concentration and size distribution in the urban atmosphere. Sci Total Environ 1999, 235:51-64.

177. Moroni B, Viti C: Grain size, chemistry, and structure of fine and ultrafine particles in stainless steel welding fumes. J Aerosol Sci 2009, 40:938-949.

178. Maynard AD, Baron PA, Foley M, Shvedova AA, Kisin ER, Castranova V: Exposure to carbon nanotube material: aerosol release during the handling of unrefined single-walled carbon nanotube material. J Toxicol Environ Health A 2004, 67:87-107.

179. Methner M, Hodson L, Dames A, Geraci C: Nanoparticle emission assessment technique (NEAT) for the identification and measurement of potential inhalation exposure to engineered nanomaterials-Part B: Results from 12 field studies. J Occup Environ Hyg 2010, 7:163-176.

180. Methner MM, Birch ME, Evans DE, Ku BK, Crouch K, Hoover MD: Identification and characterization of potential sources of worker exposure to carbon nanofibers during polymer composite laboratory operations. J Occup Environ Hyg 2007, 4:D125-D130.

181. Bello D, Wardle BL, Yamamoto N, Guzman deVilloria R, Garcia EJ, Hart AJ, Ahn K, Ellenbecker MJ, Hallock M: Exposure to nanoscale particles and fibers during machining of hybrid advanced composites containing carbon nanotubes. J Nanopart Res 2009, 11:231-249.

182. Tsai S-J, Ashter A, Ada E, Mead JL, Barry CF, Ellenbecker MJ: Airborne nanoparticle release associated with the compounding of nanocomposites using nanoalumina as fibers. Aerosol Air Quality Res 2008, 8:160-177.

183. Tsai S-J, Ashter A, Ada E, Mead JL, Barry CF, Ellenbecker MJ: Control of airborne nanoparticles release during compounding of polymer nanocomposites. NANO 2008, 3:301-309.

184. Song $Y, L i X$, Du X: Exposure to nanoparticles is related to pleural effusion, pulmonary fibrosis and granuloma. Eur Respir J 2009, 34:559-567.

185. Anon: Recommended reading. Lack of progress on nanotoxicology has been highlighted by a tragic accident in China. Nature Nanotechnology 2009, 4:533.

186. Borm P, Castranova V: Toxicology of Nanomaterials: Permanent interactive learning. Part Fibre Toxicol 2009, 6:3.

187. Hiroyuki T: Risk assessment studies of nanomaterials in Japan and other countries. Asian Pacific J Cancer Prevent 2010, 11:13-14.

188. Liao C-M, Chiang Y-H, Chio C-P: Assessing the airborne titanium dioxide nanoparticle-related exposure hazard at workplace. J Hazardous Mat 2009, 162:57-65.
189. Stone V, Aitken R, Aschberger K, Baun A, Christensen F, Fernandes T, Hansen SF, Hartmann NB, Hutchison G, Johnston $H$, et al: Engineered nanoparticles: Review of health and environmental safety (ENRHES). Edinburgh: Edinburgh Napier University; 2010 [http://ihcp.jrc.ec.europa.eu/ whats-new/enhres-final-report].

190. Tyshenko MG, Krewski D: A risk management framework for the regulation of nanomaterials. Int I Nanotechnol 2008, 5:143-160.

191. Balbus JM, Florini K, Denison RA, Walsh SA: Protecting workers and the environment: An environmental NGO's perspective on nanotechnology. J Nanopart Res 2007, 9:11-22.

192. Murr LE, Soto KF, Esquivel EV, Bang JJ, Guerrero PA, Lopez DA, Ramirez DA: Carbon nanotubes and other fullerene-related nanocrystals in the environment: a TEM study. JOM 2004, 5:28-31.

193. NIOSH: Approches to safe nanotechnology. Managing the health and safety concerns associated with engineered nanomaterials. NIOHS, CDCP, DHHS; DHHS (NIOSH) Publication 2009-125; 2009 [http://www.cdc.gov/ niosh/topics/nanotech/safenano/].

194. Trout DB, Schulte PA: Medical surveillance, exposure registries, and epidemiologic research for workers exposed to nanomaterials. Toxicology 2010, 269:128-135.

195. Schmid K, Danuser B, Riediker M: Nanoparticle usage and protection measures in the manufacturing industry-a representative survey. J Occup Environ Hyg 2010, 7:224-232.

196. Riediker M: Lessons from Nanoimpact.net conference. Presentation: Nanomaterials and worker health. Medical surveillance, exposure registries, and epidemiologic research Keystone, CO; 2010.

197. Conti JA, Killpack K, Gerritzen G, Huang L, Mircheva M, Delmas M, Harthorn BH, Appelbaum RP, Holden PA: Health and safety practices in the nanomaterials workplace: results from an international survey. Environ Sci Technol 2008, 42:3155-3162.

198. Harthorn B: Characterization of the nanotechnology workforce. Presentation: Nanomaterials and worker health. Medical surveillance, exposure registries, and epidemiologic research Keystone, CO; 2010.

199. Yeganeh B, Kull CM, Hull MS, Marr LC: Characterization of airborne particles during production of carbonaceous nanomaterials. Environ Sci Technol 2008, 42:4600-4606.

200. Tsai S-J, Ada E, Isaacs JA, Ellenbecker MJ: Airborne nanoparticle exposures associated with the manual handling of nanoalumina and nanosilver in fume hoods. J Nanopart Res 2009, 11:147-161.

201. Tsai SJ, Huang RF, Ellenbecker MJ: Airborne nanoparticle exposures while using constant-flow, constant-velocity, and air-curtain-isolated fume hoods. Ann Occup Hyg 2010, 54:78-87.

202. Ellenbecker MJS, Tsai S: Interim Best Practices for Working with Nanoparticles. Version 1: Center for High-rate Nanomanufacturing; 2008.

203. Plitzko S: Workplace exposure to engineered nanoparticles. Inhal Toxicol 2009, 21(Suppl 1):25-29.

204. Hämeri K, Laehde T, Hussein T, Koivisto J, Savolainen K: Facing the key workplace challenge: Assessing and preventing exposure to nanoparticles at source. Inhal Toxicol 2009, 21:17-24.

205. Han JH, Lee EJ, Lee JH, So KP, Lee YH, Bae GN, Lee SB, Ji JH, Cho MH, Yu IJ: Monitoring multiwalled carbon nanotube exposure in carbon nanotube research facility. Inhal Toxicol 2008, 20:741-749.

206. Lee M-H, McClellan WJ, Candela J, Andrews D, Biswas P: Reduction of nanoparticle exposure to welding aerosols by modification of the ventilation system in a workplace. J Nanopart Res 2007, 9:127-136.

207. Methner MM: Engineering case reports. Effectiveness of local exhaust ventilation (LEV) in controlling engineered nanomaterial emissions during reactor cleanout operations. J Occup Environ Hyg 2008, 5:D63-69.

208. Cena LG, Peters TM: Characterization and control of airborne particles emitted during production of epoxy/carbon nanotube nanocomposites. J Occup Environ Hygiene 2010, 8(2):86-92.

209. Schulte P, Geraci C, Zumwalde R, Hoover M, Kuempel E: Occupational risk management of engineered nanoparticles. J Occup Environ Hyg 2008, 5:239-249.

210. Huang S-H, Chen C-W, Chang C-P, Lai C-Y, Chen C-C: Penetration of 4.5 $\mathrm{nm}$ to $10 \mu \mathrm{m}$ aerosol particles through fibrous filters. J Aerosol Sci 2007, 38:719-727.

211. Golanski L, Guiot A, Rouillon F, Pocachard J, Tardif F: Experimental evaluation of personal protection devices against graphite nanoaerosols: fibrous filter media, masks, protective clothing, and gloves. Hum Exp Toxicol 2009, 28:353-359. 
212. Eninger RM, Honda T, Adhikari A, Heinonen-Tanski H, Reponen T, Grinshpun SA: Filter performance of $\mathrm{n} 99$ and $\mathrm{n} 95$ facepiece respirators against viruses and ultrafine particles. Ann Occup Hyg 2008, 52:385-396.

213. Halford B: How well do gloves and respirators block nanoparticles? C \& EN 2006, 84:14.

214. Richardson AW, Eshbaugh JP, Hofacre KC: Respirator filter efficiency testing against particulate and biological aerosols under moderate to high flow rates. Battelle Memorial Institute, Columbus, Ohio: Edgewood Chemical Biological Center, U.S. Army Research, Development and Engineering Command; ECBC-CR-085; 2006 [http://www.cdc.gov/niosh/ nppt//researchprojects/pdfs/CR-085Gardner.pdf].

215. Huang S-H, Huang Y, Chen C-W, Chang C-P: Nanoparticles penetration through protective clothing materials. 3rd International Symposium on Nanotechnology, Occupational and Environmental Health Taipei, Taiwan; 2007, Aug 29 to Sep 1 .

216. Golanski L, Guillot A, Tardif F: Are conventional protective devices such as fibrous filter media, cartridge for respirators, protective clothing and gloves also efficient for nanoaerosols? Nanosafe; 2008 [http://www. nanosafe.org/home/liblocal/docs/Dissemination\%20report/DR1_s.pdf], Dissemination Report DR-325/326-200801-1 edition: Europen Strategy for Nanosafety

217. Golanski L, Guiot A, Tardif F: Experimental evaluation of individual protection devices against different types of nanoaerosols: graphite, $\mathrm{TiO}_{2}$, and Pt. J Nanopart Res 2010, 12:83-89.

218. Gao P, Jaques PA, Hsiao TC, Shepherd A, Eimer BC, Yang M, Miller A, Gupta B, Shaffer R: Evaluation of nano- and sub-micron particle penetration through ten nonwoven fabrics using a wind-driven approach. J Occup Environ Hygiene 2011, 8:13-22.

219. Ahn K, Lee J, Tsai C, Mead J, Ellenbecker MJ: Use and efficacy of protective gloves in handling nanomaterials. 2005 [http://www.turi.org/ content/download/3270/29768/../glove\%20presentation.pdf].

220. Korniewicz DM, Kirwin M, Cresci K, Sing T, Choo TE, Wool M, Larson E: Barrier protection with examination gloves: double versus single. Am J Infect Control 1994, 22:12-15.

221. Halperin WE: The role of surveillance in the hierarchy of prevention. Am $J$ Ind Med 1996, 29:321-323.

222. NIOSH: Current Intelligence Bulletin 60. Interim guidance for medical screening and hazard surveillance for workers potentially exposes to engineered nanoparticles. 2009 [http://www.cdc.gov/niosh/docs/2009-116/ pdfs/2009-116.pdf], DHHS (NIOSH) Publication No. 2009-116.

223. Lichty P: Examples of current surveillance efforts for nanomaterial workers. Presentation: Nanomaterials and worker health. Medical surveillance, exposure registries, and epidemiologic research Keystone, CO; 2010.

224. Genaidy A, Sequeira R, Rinder M, AAR: Risk analysis and protection measures in a carbon nanofiber manufacturing enterprise: an exploratory investigation. Sci Total Environ 2009, 407:5825-5838.

225. Rengasamy S, Eimer BC, Shaffer RE: Nanoparticle filtration performance of commercially available dusk masks. J Int Soc Resp Protect 2008, 25:27-41.

226. Bałazy A, Toivola M, Reponen T, Podgorski A, Zimmer A, Grinshpun SA: Manikin-based performance evaluation of N95 filtering-facepiece respirators challenged with nanoparticles. Ann Occup Hyg 2006, 50:259-269.

227. Rengasamy S, Verbofsky R, King WP, Shaffer RE: Nanoparticle penetration through $\mathrm{NIOSH}$-approved $\mathrm{N} 95$ filtering-facepeice respirators. J Int Soc Resp Protect 2007, 24:49-59.

228. Rengasamy S, Eimer BC, Shaffer RE: Comparison of nanoparticle filtration performance of $\mathrm{NIOSH}$-approved and $\mathrm{CE}$-marked particulate filtering facepiece respirators. Ann Occup Hyg 2009, 53:117-128.

229. Rengasamy S, King WP, Eimer BC, Shaffer RE: Filtration performance of $\mathrm{NIOSH}$-approved $\mathrm{N} 95$ and P100 filtering facepiece respirators against 4 to 30 nanometer-size nanoparticles. J Occup Environ Hyg 2008, 5:556-564

doi:10.1186/1745-6673-6-7

Cite this article as: Yokel and MacPhail: Engineered nanomaterials: exposures, hazards, and risk prevention. Journal of Occupational Medicine and Toxicology 2011 6:7.

\section{Submit your next manuscript to BioMed Central and take full advantage of:}

- Convenient online submission

- Thorough peer review

- No space constraints or color figure charges

- Immediate publication on acceptance

- Inclusion in PubMed, CAS, Scopus and Google Scholar

- Research which is freely available for redistribution 